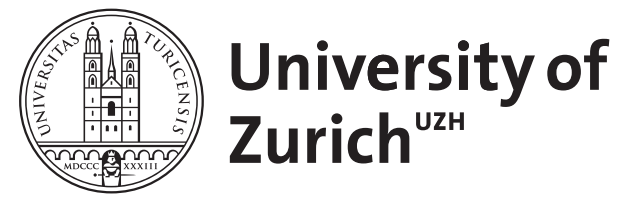

The endogenous price dynamics of emission allowances and an application to CO2 option pricing

Chesney, Marc ; Taschini, Luca

DOI: https://doi.org/10.1080/1350486X.2011.639948

Posted at the Zurich Open Repository and Archive, University of Zurich ZORA URL: https://doi.org/10.5167/uzh-49682

Journal Article

Originally published at:

Chesney, Marc; Taschini, Luca (2012). The endogenous price dynamics of emission allowances and an application to CO2 option pricing. Applied Mathematical Finance, 19(5):447-475.

DOI: https://doi.org/10.1080/1350486X.2011.639948 
This article was downloaded by: [LSE Library], [Luca Taschini]

On: 21 February 2012, At: 08:55

Publisher: Routledge

Informa Ltd Registered in England and Wales Registered Number: 1072954 Registered

office: Mortimer House, 37-41 Mortimer Street, London W1T 3JH, UK

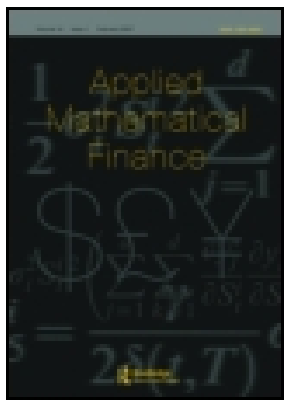

\author{
Applied Mathematical Finance \\ Publication details, including instructions for authors and \\ subscription information: \\ http://www.tandfonline.com/loi/ramf20
}

\title{
The Endogenous Price Dynamics of Emission Allowances and an Application to Option Pricing
}

\author{
Marc Chesney ${ }^{\text {a b } \& \text { Luca Taschini }}{ }^{c}$ \\ a Department of Banking and Finance, University of Zurich, \\ Zurich, Switzerland \\ ${ }^{\mathrm{b}}$ Swiss Finance Institute, Zurich, Switzerland \\ c The Grantham Research Institute on Climate Change and the \\ Environment, London School of Economics and Political Science, \\ London, UK
}

Available online: 21 Feb 2012

To cite this article: Marc Chesney \& Luca Taschini (2012): The Endogenous Price Dynamics of Emission Allowances and an Application to Option Pricing, Applied Mathematical Finance, DOI:10.1080/1350486X.2011.639948

To link to this article: http://dx.doi.org/10.1080/1350486X.2011.639948

\section{GFirst}

\section{PLEASE SCROLL DOWN FOR ARTICLE}

Full terms and conditions of use: http://www.tandfonline.com/page/terms-andconditions

This article may be used for research, teaching, and private study purposes. Any substantial or systematic reproduction, redistribution, reselling, loan, sub-licensing, systematic supply, or distribution in any form to anyone is expressly forbidden.

The publisher does not give any warranty express or implied or make any representation that the contents will be complete or accurate or up to date. The accuracy of any instructions, formulae, and drug doses should be independently verified with primary sources. The publisher shall not be liable for any loss, actions, claims, proceedings, demand, or costs or damages whatsoever or howsoever caused arising directly or indirectly in connection with or arising out of the use of this material. 


\title{
The Endogenous Price Dynamics of Emission Allowances and an Application to $\mathrm{CO}_{2}$ Option Pricing
}

\author{
MARC CHESNEY $^{*, * *} \&$ LUCA TASCHINI ${ }^{\dagger}$ \\ *Department of Banking and Finance, University of Zurich, Zurich, Switzerland, **Swiss Finance Institute, \\ Zurich, Switzerland, ${ }^{\dagger}$ The Grantham Research Institute on Climate Change and the Environment, London \\ School of Economics and Political Science, London, UK
}

(Received 2 September 2009; in revised form 17 June 2011)

\begin{abstract}
Market mechanisms are increasingly being used as a tool for allocating somewhat scarce but unpriced rights and resources, and the European Emission Trading Scheme is an example. By means of dynamic optimization in the contest of firms covered by such environmental regulations, this article generates endogenously the price dynamics of emission permits under asymmetric information, allowing inter-temporal banking and borrowing. In the market, there are a finite number of firms and each firm's pollution emission follows an exogenously given stochastic process. We prove the discounted permit price is a martingale with respect to the relevant filtration. The model is solved numerically. Finally, a closed-form pricing formula for European-style options is derived.
\end{abstract}

KEY WORDS: Asymmetric information, environmental finance, European Emission Trading Scheme, trading decisions

\section{Introduction}

During the last decade we have been witness to a significant increase in the attention given by both policymakers and regulators to market-based environmental policy instruments. These are aimed at internalizing costs that previously had been met by those external to the production process (see Pigou, 1918). Such policy instruments have emerged as a more cost-effective alternative to conventional command-andcontrol standards, which had dominated the previous two decades of environmental laws and regulations. ${ }^{1}$ A programme for tradable permits generates a clear price signal that guides firms in developing and evaluating new, more efficient pollution control technologies. From a political perspective, emission-trading programmes are perceived as fairer, and thus more acceptable, than other forms of environmental regulation as they promote decentralized decision-making.

Correspondence Address: Luca Taschini, The Grantham Research Institute on Climate Change and Environment, London School of Economics and Political Sciences, London, UK. Email: 1.taschini1@1se.ac.uk 


\section{M. Chesney and L. Taschini}

One of the first references to market-based techniques for dealing with pollution problems can be found in the seminal works of Coase (1960) and Dales (1968). In these papers, the pollution abatement problem is viewed within an economic, costbenefit framework in conjunction with the concept of property rights: Their essays propose the basic idea of tradeable permits. Based on such an idea, Montgomery (1972) provides a rigorous theoretical justification of how a market-based approach leads to the efficient allocation of abatement costs across various sources of pollution. Necessary and sufficient conditions for market equilibrium and efficiency are derived given the setting of multiple profit-maximizing firms who attempt to minimize total compliance costs. Theoretical aspects that Montgomery (1972) does not discuss have been addressed by several studies as reported in Taschini (2010). The author reviews fundamental concepts in environmental economics and overviews recent attempts at developing valid price models for emission permits. Literature focusing on the economic and policy aspects of this new market-based mechanism is extensive, but an explicit study of the dynamics of the emission permit price in the presence of market uncertainty is an almost unexplored area. Most of the present research relies on the theoretical result - demonstrated and extensively discussed by Cronshaw and Kruse (1996) and Rubin (1996) - that, in an efficient market, the equilibrium price of the emission permits (or allowances) is equal to the marginal costs of the cheapest pollution abatement solution. This statement underpins the belief that a high price level for emission permits brings about relevant companies with lower marginal abatement costs in order to exploit consequent price differences. Such companies make profits by lowering the level of offending gases more than is necessary to comply with regulations and subsequently sell their spare permits. This result, however, is due to stylized models that ignore uncertainty. Schennach (2000) attempts to overcome this limitation by extending Rubin's model (1996). This article is one of the first that implicitly analyses the permit price in a stochastic, continuous-time and infinite-time horizon model. In line with previous research, in the model of Schennach a level of pollution abatement is chosen such that the current marginal cost of abating equals the current permit spot price. Though the author does not provide an exact analytic solution for the optimization problem in the presence of uncertainty, she conjectures that the actual path of permit price and pollution emissions may be quite different from their expected path. When new information becomes available, the optimization problem has to be reevaluated, possibly generating cusp or discontinuity in the path of pollution emissions and of the price of emission permits. Anticipating our results, this is what we obtain in the numerical solution of our model in Section 5.

Recently, in an effort to bridge the gap between theory and observed market-price behaviour, an increasing number of empirical studies have been investigating the historical time series of the permit price. In Daskalakis et al. (2009), several different diffusion and jump-diffusion processes were fitted to the European carbon dioxide $\left(\mathrm{CO}_{2}\right)$ futures time series. Benz and Trück (2009) analyse the short-term spot price behaviour of $\mathrm{CO}_{2}$ permits employing a Markov-switching model to capture the heteroskedastic behaviour of the return time series. In contrast, Paolella and Taschini (2008) advocate the use of a new GARCH-type structure for the analysis of inherent heteroskedastic dynamics in the returns of $\mathrm{SO}_{2}$ in the United States and of $\mathrm{CO}_{2}$ emission permits in the European Emission Trading Scheme (EU ETS). 
With a precise focus on the European emission market and in an attempt to develop a valid dynamic price model, Seifert et al. (2008) and Fehr and Hinz (2006) elaborate a quantitative analysis of the $\mathrm{CO}_{2}$ permits price founded on the pivotal results from environmental economics literature. These are two interesting papers in the increasing body of literature on environmental finance, a new strand of research that is focusing on financial and quantitative issues originating from solutions proposed by environmental economists. In particular, Seifert et al. (2008) consider one representative agent who decides whether to spend money on lowering emission levels. The model is based on the optimal abatement decision of an affected company, therefore it very much depends on its total expected emissions. With a distinction between long-term and short-term abatement measures, Fehr and Hinz (2006) concentrate on the energy sector considering $n$ affected utilities that decide their abatement levels by relying on the cheapest possible abatement option in the short term, that is so-called fuel-switching. ${ }^{2}$

In our article, we generate endogenously the price dynamics of marketable permits under asymmetric information, allowing banking and borrowing. The basic set-up is a permit market lasting a finite $T$ number of periods. In common with the lastmentioned paper, we differentiate short-term and long-term abatement measures. As extensively discussed in Section 3, a few options are available to the majority of affected companies and even fewer fall into the list of so-called short-term abatement possibilities. As a result, in the short-run it is relatively difficult to modify production processes or outputs. Accordingly, we assume each firm's pollution emission follows an exogenously given stochastic process. There are a finite number of firms and the initial allocation of permits in each period to these firms is pre-determined and publicly known. In each period, a firm knows its own accumulated pollution level and those of the other firms up to the previous period. This allows us to model the asymmetry in the information. At the end of the time $T$, firms reconcile their permit holding with the accumulated emissions: if a firm's permit holding is less than its accumulated pollution, it has to pay a penalty for each permit in shortage at a pre-determined rate. The firm's strategy is to choose the optimal number of permits to buy or sell in each period up to time $T-\Delta t$. The firms' trading decisions and the market-clearing condition in each period determines the equilibrium permit price and the instantaneous volume of emission permits traded in the market. We prove that the price path of emission permits depends on the future probability of a shortfall in permits, the penalty that will be paid in the event of a shortfall, and the discount rate. The intuition is that the price of emission permits at each time $t$ should reflect the firms' perception about scarcity or excess of permits in the market based on the information available at time $t$.

Optimal strategies are readily computable in a static and deterministic framework. Conversely, regulatory uncertainties and uncertainties in the evolution of the pollution processes make an identification of the best strategy less straightforward in the short term. Apart from technological issues (see the discussion in Section 3) and regulatory uncertainties, financial concerns are also beginning to creep in. Observed extreme volatility in the European and US permit markets suggests an urgent need for the development of effective hedging techniques. ${ }^{3}$ In addition, the numerous risks related to market-based products highlight the importance of developing appropriate riskmanagement tools for those companies that are subject to environmental programmes, as well as to specialized traders. More importantly, a valid price model is required for any financial instruments or project whose value derives from the future $\mathrm{CO}_{2}$ spot 
permit price. Extremely relevant examples are project-based investments (see the discussion in Section 6), that at regular intervals return emission reduction certificates, yielding a payoff that depends on the $\mathrm{CO}_{2}$ permit market price.

The organization of the remaining sections of this article is as follows: Section 2 briefly introduces market-based products as instruments for pollution control and describes the EU ETS market. Section 3 addresses the fundamental distinction between long-term and short-term abatement policies. Section 4.1 presents the model and its formulation for the basic case of one company with emission-trading opportunity only at time 0 . Then, we extend the model to account for the presence of the firms' permit trading decisions and asymmetric information. Section 5 numerically solves the model. Section 6 derives a closed-form pricing formula for European-style options. Section 7 concludes.

\section{Environmental Programme for Air-control}

A tradable permits scheme for air pollution control is constructed as follows: Emission allowances are denominated in units of a specific pollutant (e.g. in tons of $\mathrm{CO}_{2}$ ). Emission permits are issued to relevant facilities in amounts proportional to their size and emissions according to a referred year as baseline. For a detailed discussion about initial allocation criteria see Bahn et al. (1999) and references therein. At regular intervals, facilities submit emission reports for their compliance period, at the end of which facilities must own sufficient permits to cover their emissions. This implies that each facility must hold at least as many valid credits as emissions during the compliance period. A penalty is levied if a facility does not deliver a sufficient amount of allowances at the end of the compliance period. The payment of a fine does not remove the obligation to achieve compliance, which means that undelivered permits have to be handed in. Having been used to cover emissions, these credits are then deleted from the regulatory compliance system, preventing subsequent use or transfer. The compliance date marks the end of each period for which a facility has to file an emissions report, which is due on the certification date.

The largest and most important emission-trading programme was developed by the European Union to facilitate implementation of the Kyoto Protocol. The EU ETS covers more than five different industrial sectors and almost 12,000 installations in 25 countries, responsible for nearly half of the EU's $\mathrm{CO}_{2}$ emissions. They have been allocated allowances giving them the right, over the first phase (2005-2007), to emit 6.6 billion tons of $\mathrm{CO}_{2}$. The second phase coincides with the first Kyoto commitment period, beginning in 2008 and continuing through 2012. The third phase will run from 2013 to 2020. The EU ETS has created de facto property rights for emissions that are freely tradable. All permits are transferable, that is a facility that generates excess permits by reducing emissions below its allocated levels can sell those extra credits to other relevant entities. In addition to the so-called spatial trading, ${ }^{4}$ both schemes allow for inter-temporal trading, so that companies can save their allowances for use in the future. This is reflected by a larger time flexibility for pollution-control investments. In particular, starting from phase II the EU ETS allows within phase banking, that is allowances can be banked from 1 year to the next, and from one phase to the next. Unused allowances, however, are not valid during the following phase. 


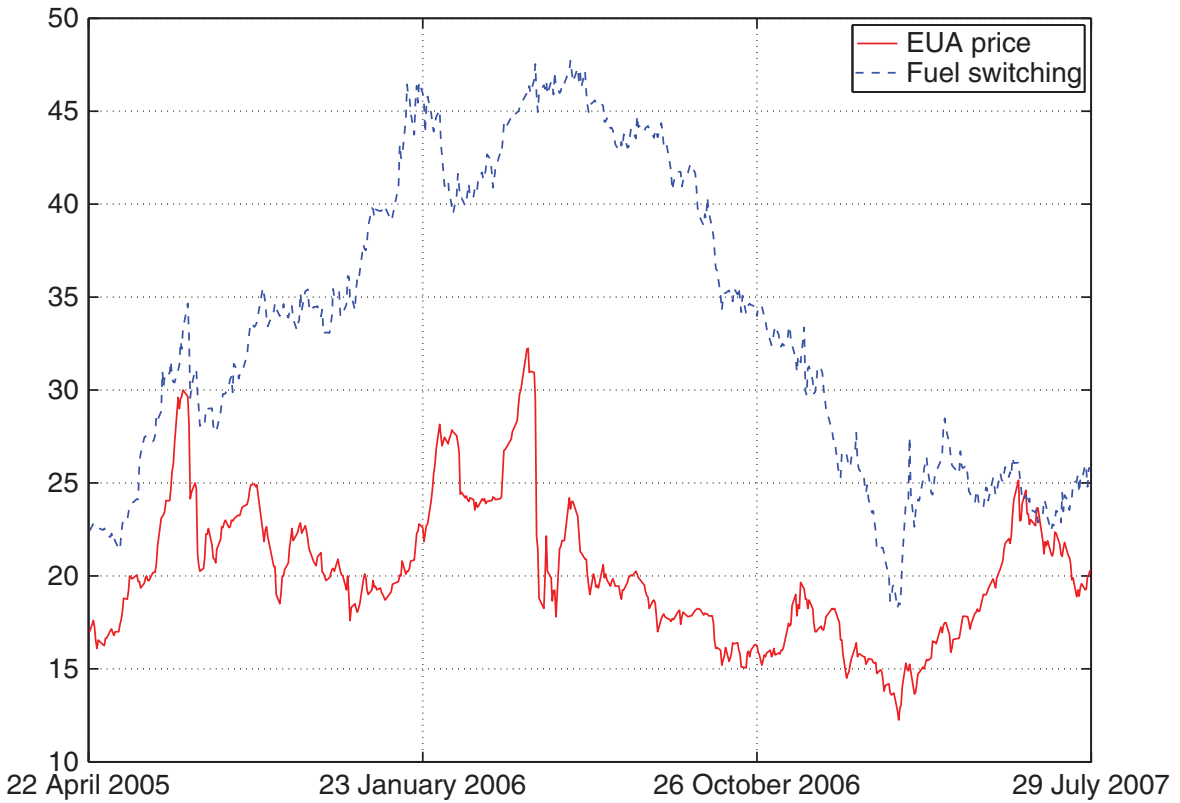

Figure 1. The solid line is the empirical price of the $\mathrm{CO}_{2}$ emission permits. The dashed line is the cost to switch from cheap-but-dirty coal to expensive-but-cleaner natural gas (it is an approximation of the marginal cost of abatement). The historical coal-to-gas switching price is calculated by considering the ratio $\left(h_{\mathrm{g}} G_{\mathrm{t}}-h_{\mathrm{c}} C_{\mathrm{t}}\right) /\left(e_{\mathrm{c}}-e_{\mathrm{g}}\right)$, where $h_{\mathrm{c}}$ and $h_{\mathrm{g}}$ are average heating rates of coal and gas; $e_{\mathrm{c}}$ and $e_{\mathrm{g}}$ correspond to average $\mathrm{CO}_{2}$ emissions for coal and gas, respectively. In Europe standard heat factors are $h_{\mathrm{c}}=0.378 \mathrm{t}_{\text {coal }} / M W h$ and $h_{\mathrm{g}}=1.92 M W h_{\text {therm }} / M W h$. The average $\mathrm{CO}_{2}$ emission factors for coal and gas are $e_{\mathrm{c}}=0.897 t_{\mathrm{CO}_{2}} / M W h$ and $e_{\mathrm{g}}=0.388 t_{\mathrm{CO}_{2}} / M W h$. $C_{\mathrm{t}}$ and $G_{\mathrm{t}}$ are the time series of coal and gas prices. Time series was run from April 2005 to July 2007.

The economic incentives embedded in the tradable permits are designed to force companies to participate in the permits market. This leads to a theoretical equalization of marginal abatement costs across different pollution sources. However, currently the observed permit price does not coincide with the expected theoretical level (see Figure 1). ${ }^{5}$ Though this might be ascribed to a market that is in the initial stage of development, in section 3 we will attempt to address directly the reasons why this mismatch is present.

\section{Abatement Opportunities in the Short Term}

According to the market-based approach that we have described, a generating unit is endowed with high flexibility in determining the best strategy of achieving compliance under the programmes: each firm faces a basic choice between buying (or selling) allowances, and reducing emissions through the use of alternative technologies. Three general classes of techniques for the physical reduction of emissions are available. Firstly, emissions can be reduced by lowering the output scale. Secondly, 
the production process or the inputs used - e.g. fuels - can be altered. Finally, tailend cleaning equipment can be installed to remove pollutants from effluent streams before they are released into the environment. European firms, in order to accomplish Europe's severe environmental regulations, have mostly achieved high environmental standards either in production processes or in the reduction of offending gases released as a by-product into the air. This implies that currently it is relatively difficult to actively reduce further on pollution emissions in the short term. Here, we do not consider the situation of an exogenous slowdown of the economy. Therefore, the first abatement alternative can be considered as the exception rather than the rule (see Hidalgo et al. (2005) and Szabö et al. (2006) for a more comprehensive discussion).

A market-based approach leads to an efficient allocation of abatement costs across different pollution sources, as shown by Montgomery (1972). However, this heavily depends on the implicit assumption that emission allowances are perceived as a perfect substitute for any technological abatement solution, for instance, the installation of scrubbers on smokestacks to extract noxious fumes as solid residues. ${ }^{6}$ This only holds true in an efficient market with no uncertainty. Those facilities that are affected, on the contrary, face considerable uncertainty. Chao and Wilson (1993) show that companies perceive abatement technologies - in particular scrubber plants for sulfur dioxide - as inferior substitutes for emission allowances. In contrast to emission permits, investments in pollution-reduction infrastructures are irrevocable commitments that last for decades and typically need some lead time in order to become effective. (For a more extensive discussion refer to Farzin and Kort (2000) and Zhao (2003).) The purchase of allowances is adjustable to changing market conditions whereas a scrubber might be underutilized if demand falls. Moreover, the cost of a scrubber might be excessive following a fall in permit price. Hence, since pollution abatement technologies are often expensive, durable and irreversible investments, they are not commonly deemed to be a perfect substitute for emission permits. In the EU ETS, fuel-burning energy producers have one of the cheapest abatement alternatives, that is so-called fuel-switching. Though this change in the production process has been implemented in few installations, it is hard to justify it took place only based on the then $\mathrm{CO}_{2}$ price level especially when the permit price was hovering above zero. Further, there are several reasonable explanations that can provide elements of irreversibility to fuel-switching decisions. For instance, Insley (2003) discusses the case of fuel contracts with long maturities in order to lock in a particular price premium.

Taking a real option perspective, one could say that the equilibrium price of emission permits should reflect the marginal cost of pollution abatement and the value of the option to delay a large (irreversible or reversible) expenditure on modifying the production process or on pollution abatement equipment. As long as buying permits is perceived the most flexible alternative, the price of emission permits should reflect the probability of having to buy additional permits to satisfy regulations, which is the focus of this article. Plausibly, other sources of uncertainties, for instance regulatory uncertainty or an economic shock, can distort the theoretical equilibrium price, but the overall effect would always be a mismatch. Following this line of reasoning, we develop an equilibrium model for the short-term permit price. We propose possible model extensions for the inclusion of general technological abatement measures or production management decisions based on daily $\mathrm{CO}_{2}$ price movements, but we leave this investigation for future research. 


\section{The Formal Model}

\section{1 'Wait-and-see' for One Company}

In the tradable permit price modelling, as outlined by Montgomery (1972), the existence of an efficient market has been generally assumed. This leads to an equalization of marginal abatement costs across the different pollution emitters and to an emergence of an alignment of companies' interests with those of a representative agent (as in Seifert et al. (2008)), or with a social planner (as in Fehr and Hinz (2006)). ${ }^{7}$ Employing the existence of a single representative firm in the market as in Seifert et al. (2008), we model the permit price process in a simplified setting where trading is only possible at the inception of an environmental programme that has a finite length $T$. Addressing the cost minimization problem, we derive the permit price in analytic form.

Let $(\Omega, \mathcal{F}, \mathbb{P})$ be the probability space, $\mathcal{F}=\left(\mathcal{F}_{0}\right)$ the filtration where $\mathcal{F}_{0}=\sigma\left(Q_{0}\right)$. We denote with $Q_{0}$ the initial pollution level and with $X_{0}$ the quantity of permits that the company buys $\left(X_{0}>0\right)$ or sells $\left(X_{0}<0\right)$ at time 0 , and with $N$ the initial permits endowment. We label $\delta_{0}$ the overall net amount of permits for the company at initial time, where $\delta_{0}=N+X_{0}$ and it gives the company the right to emit a volume of offending gases up to such a level. We assume that the firm continuously emits offending gas according to a stochastic exogenous process over the period $[0, T]$. The process evolves accordingly to a geometric Brownian motion:

$$
\frac{d Q_{t}}{Q_{t}}=\mu d t+\sigma d W_{t}, \quad \text { or equivalently } \quad Q_{t}=Q_{0} e^{\left(\mu-\frac{\sigma^{2}}{2}\right) t+\sigma W_{t}},
$$

where $\mu$ and $\sigma$ are the instantaneously constant drift term and the constant volatility of the pollution process, respectively. The assumption of a geometric Brownian motion leads to a natural interpretation of its parameters. $Q_{0} \cdot \int_{0}^{T} e^{\mu t} d t$ can be interpreted as the expected cumulated pollution level between 0 and $T$, while the drift and the volatility are the trend and the uncertainty associated with the emission process. Also, the EU ETS concerns a total volume control of pollution because of the existence of a threshold in the stock of $\mathrm{CO}_{2}$ in the atmosphere and not in the flow. In fact, we are interested in a (non-decreasing) quantity that measures the accumulated pollution volume. Therefore, the assumption of a geometric Brownian motion is not unrealistic, and the quantity $\int_{0}^{t} Q_{s} d s$ is precisely what we look for. Besides, it has also nice mathematical properties. Thereby, a negative $\mu$ implies a lower rate of accumulation of pollution maybe due to a previous technological improvement, whereas $\sigma$ measures the uncertainty about the accumulated pollution volume. A natural extension of the model would be the introduction of an endogenous pollution process. This would account for the situation where firms are able to respond to changes in current prices and in expectations of future prices by adjusting their emission levels. As discussed before, this will not be the case under our study that concentrates on the short term.

As described in Section 2, in order to pollute legally, the company must have enough allowances by the end of the period $T$. If the firm fails to achieve compliance, it will pay a penalty equal to $P$. More precisely, in the EU ETS penalty costs may occur at the end of every year. However, the European Directive allows a 1-year borrowing within a trading period. This means that companies are allowed to use allowances with future 
maturity for compliance in the current year without having to buy the permits in the market. It is thus not unreasonable to assume that companies will not pay penalties for a shortfall within a particular trading period. At the end of the period we expect either a shortage or a surplus situation (or possibly a perfect match) between the issued emission allowances and the verified pollution level. Inevitably, the company will be either holding worthless emission allowances or paying the price for being uncovered i.e. the penalty $P$ times the number of uncovered tons - or be totally and perfectly hedged. Yet, as this last possibility is quite unlikely, the final cash outflow boils down to a binary outcome. In fact, the firm's final cost in a wait-and-see situation without any trading opportunity during the period $[0, T]$ is

$$
\max \left\{0,\left(\int_{0}^{T} Q_{s} d s-\delta_{0}\right)\right\} \cdot P
$$

where $\int_{0}^{T} Q_{s} d s$ is the firm final accumulated pollution level. From expression (2) it is obvious that emission allowances - like many other marketable permits - are to all intents option contracts. Several features shared with standard options contracts are discussed in the forthcoming numerical section.

Given the initial endowment of permits and the expected net position in future permits, a firm minimizes its costs at the inception of the period. The total cost is simply the sum of the cash flows at initial time (or minus the proceeds from permits sales) and the potential penalties at the end of the programme. Therefore, the resulting minimization problem is

$$
\min _{\left\{X_{0}\right\}}\left\{S_{0} \cdot X_{0}+e^{-\eta T} \mathbb{E}_{\mathbb{P}}\left[\left(\int_{0}^{T} Q_{s} d s-\delta_{0}\right)^{+} \cdot P \mid \mathscr{F}_{0}\right]\right\},
$$

where the expectation is taken under the historical probability measure $\mathbb{P}^{8} \eta$ is the discount rate - the weighted average cost of capital - and $S_{0}$ is the permit price (known) at time $t=0$. Problem (3) expresses in quantitative terms the firm's strategy described in Section 1: the firm's aim is to have a portfolio of emission permits at-the-money at time $T$.

In order to express the permit price in analytic form, we rely on Geman and Yor (1993) and write the objective function as follows:

$$
\begin{array}{r}
\mathrm{H} \equiv\left\{S_{0} \cdot X_{0}+e^{-\eta T} \mathbb{E}_{\mathbb{P}}\left[\left(\int_{0}^{T} Q_{s} d s-N-X_{0}\right)^{+} \cdot P\right]\right\} \\
\text { with } \int_{0}^{T} Q_{s} d s=\frac{4}{\sigma^{2}} \cdot Q_{0} \int_{0}^{\sigma^{2} T / 4} e^{2\left(\widetilde{W}_{u}+z u\right)} d u=: \frac{4}{\sigma^{2}} \cdot Q_{0} \cdot A_{\sigma^{2} T / 4}^{z} \\
z:=\frac{2 v}{\sigma}, \quad v:=\frac{1}{\sigma} \cdot\left(\mu-\frac{\sigma^{2}}{2}\right) \quad \text { and } \quad \widetilde{W}_{u}:=\frac{\sigma}{2} W_{4 u / \sigma^{2}} \quad \text { is a Brownian motion. }
\end{array}
$$


Finally, we denote $A_{T}^{v}=\int_{0}^{T} e^{2\left(W_{s}+v s\right)} d s$.

Computing the first-order condition (FOC), $X_{0}$ satisfies the following equation (the detailed derivation is in Appendix A):

$$
S_{0}=e^{-\eta T} \cdot P \cdot \int_{\delta_{0} \cdot \sigma^{2} / 4 Q_{0}}^{\infty} \mathbb{P}\left[A_{\sigma^{2} T / 4}^{z} \in d x\right] .
$$

It is observable that the emission allowance spot price is a function of the penalty level and the probability of a permit shortage situation. The functional form of such probability is known, but unfortunately is problematic to evaluate numerically. For illustrative purposes, therefore, we let $T$ be an arbitrary small time interval $(T=\Delta t)$ and then compute the discrete approximation of $\int_{0}^{T} Q_{s} d s$. This enables us to derive a more intuitive analytical form for the permit spot price (the detailed derivation is in Appendix A):

$$
S_{0}=e^{-\eta T}\left[P \cdot \Phi\left(d_{-}\right)\right], \quad \text { where } \quad d_{-}=\frac{\ln \left(Q_{0} \cdot \Delta t / \delta_{0}\right)+\left(\mu-\frac{\sigma^{2}}{2}\right) \Delta t}{\sigma \sqrt{\Delta t}},
$$

and $\Phi(x)$ is the standard cumulative distribution function $\Phi(x)=\frac{1}{\sqrt{2 \pi}} \int_{-\infty}^{x} e^{-\frac{u^{2}}{2}} d u$. In Equation (5), the price of the emission permits reflects the probability of having to buy additional permits, i.e. the probability to not satisfy regulation, which corresponds to the event $\left\{\int_{0}^{T} Q_{s} d s>\delta_{0}\right\}$. $^{9}$

In Figure 2, we give a graphical interpretation of Equation (5). Let us consider the case where the permit price, $S_{0}$, is (exogenously) given. The objective here is to investigate the impact of different price level (low price, high price) on the permit trading strategy, $X_{0}$. The objective of each regulated company is to achieve compliance at minimum cost. A regulated firm, in principle, should buy the minimum or sell the maximum

(a)

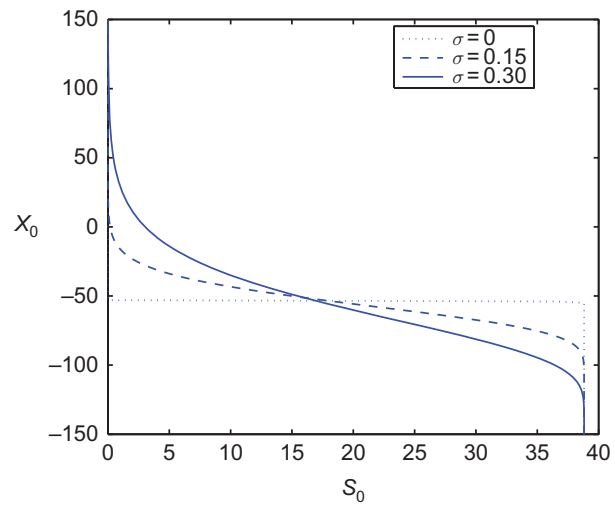

(b)

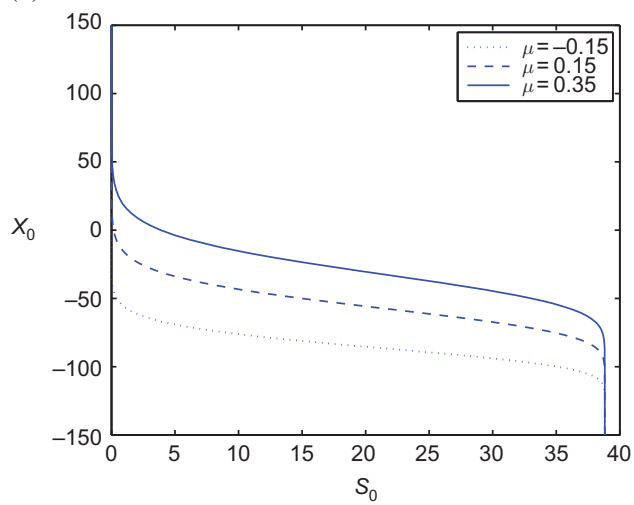

Figure 2. Plot of the number of permits, $X_{0}$, as a function of the permit price, $S_{0}$. We plot the permit price for $(a)$ different $\left\{\sigma: \sigma \in \mathbb{R}^{+}\right\}$, and $(b)$ different $\{\mu: \mu \in \mathbb{R}\}$, keeping all other parameters constant. When not otherwise specified in the legend, the parameters used in this example are $N=170, P=40, \sigma=0.15, \mu=0$, and the initial emission level is $Q_{0}=100$. 
number of permits that guarantees such objective. By considering the minimization problem in Equation (3) and using an arbitrary set of parameters, Figure 2 explains the logic behind this argument. Under certainty, the firm achieves perfect compliance by selling 50 permits, i.e. $X_{0}=-50$. In such a scenario, this is the optimal solution: the firm is not better off by selling one extra unit more or less. Moreover, the trading strategy is independent of the permit price level, $S_{0}$. Under uncertainty, instead, there is a trade-off between the permit price and the opportunity cost to be in compliance with the regulations. Contingent on the permit price, the firm may be better off by trading more or less permits. When the price is high, the company sells more (buys less) permits and bears the potential costs to be non-compliant. Conversely, when the price is low, the company sells less (buys more) permits. Such a trading behaviour is graphically represented by an inverse ' $\mathrm{S}$ '. This S-shaped graph is more pronounced when $\sigma$ is higher $(a)$ and it is simply shifted upward and downward depending on the parameter $\mu(b)$. It is worth noticing that this pattern resembles the graphical results of the equilibrium spot price in Seifert et al. (2008).

\subsection{Two-companies and Multi-periods Trading}

A market for tradable permits is clearly different from the oversimplified situation of a representative agent described above. Not just one representative agent, but different companies operate at the same time on the market. Therefore, the resulting interaction of the companies' optimization strategies must be properly taken into account. Furthermore, as discussed in Section 3, several technical and operational factors contribute to the uncertainty observed in emission levels and to the perception of a larger flexibility for the emission permits compared with other abatement measures. These factors include also uncertainty in the demand for companies' goods and services. This results in a variation in the production activity levels, measurement and monitoring uncertainty. These, coupled with imperfect information regarding emission levels (which is explicitly modelled in this article), typically lead to the facilities ending up either short of or in excess of emission permits. Both of these are highly undesirable scenarios. The former results in excessive emissions in the environment in conjunction with high violation penalties for the facilities while the latter represents unrealized productive and/or market value for the firm. As a result, facilities are forced to participate in the market in order to reconcile their emission credit accounts. They do this by either selling or buying permits. Historical price evidence suggests that many of the affected firms dynamically adjust their positions, thus ensuring compliance, by purchasing or selling the difference between their allowance allocation and their expected net future emission. ${ }^{10}$ In what follows we extend the basic model, accommodating it to the interaction of two firms that trade in a multiperiod setting and to the presence of asymmetric information regarding emission levels. To simplify matters, we do not account for the possibility of trading the emission certificates generated by Joint Implementation or Clean Development Mechanism projects. ${ }^{11}$

Let $\left(\Omega, \mathcal{F},\left\{\mathcal{F}_{t}\right\}, \mathbb{P}\right)$ be the probability space, $\mathcal{F}=\left(\mathcal{F}_{t}\right)_{t \geq 0}$ be the filtration where $\mathcal{F}_{t}=\left\{\cap_{i \in I} \mathscr{I}_{t}^{i}\right\}, \mathcal{F}_{t}^{i}=\left\{\mathcal{G}_{t}^{i} \cup_{j \in \mathscr{I}, j \neq i} \mathcal{G}_{t-1}^{j}\right\}, \mathcal{G}_{t}^{i}=\sigma\left(Q_{s}^{i}, s \in[0, t]\right)$, and $\mathscr{I}=1, \ldots, I$. Each firm continuously emits offending gas accordingly to an exogenous process: 


$$
\frac{d Q_{i, t}}{Q_{i, t}}=\mu_{i} d t+\sigma_{i} d W_{i, t}
$$

where we assume $d W_{i, t} \cdot d W_{j, t}=0$ for $\{i, j \in \mathscr{I}, i \neq j\} .{ }^{12}$ We denote with $X_{i, t}$ and $N_{i}$, respectively, the quantity of permits that the $i$ th company buys or sells and the initial permits endowment. In a cap-and-trade, as the EU ETS, the GHG reduction target is settled at the inception of each phase; therefore, the supply side of pollution permits is indeed fixed and for $I=\{1,2\}$ is equal to $N=N_{1}+N_{2}$. The net amount of permits that the $i$ th company possesses at time $t$ is denoted by

$$
\delta_{i, t}:=N_{i}+\sum_{s=0}^{t} X_{i, s} \quad \forall \quad t=1,2, \ldots, T-1, \quad i=\{1,2\},
$$

where $\sum_{s=0}^{t} X_{i, s}$ is the sum of the marginal quantities of emission permits bought minus those sold by company $i$ excluding the initial permit endowment.

Given that the total number of permits is fixed, the market-clearing condition is

$$
\delta_{1, t}+\delta_{2, t}=N \quad \text { or in another form } \quad X_{1, t}=-X_{2, t} \quad \forall \quad t=0,1, \ldots, T-1 .
$$

Condition (6) implies that in equilibrium the permit positions are in zero net supply. Hence, it satisfies the competitive equilibrium condition that requires equality between supply and demand for pollution permits in the market. We label the $i$ th net-accumulated pollution volume at time $t$ as $\int_{0}^{t} Q_{i, s} d s-\delta_{i, t-1}$. We explicitly model the presence of asymmetric information regarding emission levels as follows: In each period $t \in[0, T-1]$, company $i$ knows its own net-accumulated pollution level, $\int_{0}^{t} Q_{i, s} d s-\delta_{i, t-1}$, and that of the other firm up to the previous period, $\int_{0}^{t-1} Q_{j, s} d s-$ $\delta_{j, t-1}$. In other words, the asymmetry means a lag-effect on the information available to a firm about the other firm's emissions. This certainly holds in practice, since firms usually do not know precisely how much other firms (not necessarily competitors) pollute. We consider the particular case of a lag-size equal to one unit of time. Without loss of generality, we can extend the model to the case where the lag-size equals $n$ units of time, where $n>1$. This is discussed in Section 5 .

At time $T$, if neither of the company is in a permit need, all left-over permits have zero value. Conversely, if at least one of the firms is in permit shortage, since by law all covered companies have to surrender sufficient credits at time $T$, the permit has a value equal to the penalty level $P$. This holds assuming that each firm in shortage is indifferent to purchase permits and to penalty payments. This implies we assign market power to firms in excess of emission permits. Analytically, the permit value at time $T$ is

$$
S_{T}=\left\{\begin{array}{lllll}
0 & \text { if } & \forall & i \in \mathscr{I} & \int_{0}^{T} Q_{i, s} d s \leq \delta_{i, T-1} \\
P & \text { if } \quad \exists & i \in \mathscr{I} & \int_{0}^{T} Q_{i, s} d s>\delta_{i, T-1}
\end{array} .\right.
$$

In accordance with the emission market construction at time $T$, if company $i$ is in permit excess, it can sell to company $j$ what the latter wants to buy: 


$$
\min \left\{\left(\delta_{i, T-1}-\int_{0}^{T} Q_{i, s} d s\right)^{+},\left(\int_{0}^{T} Q_{j, s} d s-\delta_{j, T-1}\right)^{+}\right\}=: \Gamma
$$

On the other hand, if company $i$ is in permit shortage, it can buy from company $j$ what the latter wants to sell:

$$
\min \left\{\left(\int_{0}^{T} Q_{i, s} d s-\delta_{i, T-1}\right)^{+},\left(\delta_{j, T-1}-\int_{0}^{T} Q_{j, s} d s\right)^{+}\right\}=: \Pi
$$

However, if $\left(\int_{0}^{T} Q_{1, s} d s-\delta_{1, T-\Delta t}\right)^{+}-\Pi>0$, by law company $i$ has to pay $P$ per unit of emitted pollution not covered by the permits. Thus, combining Equations (8) and (9), we can simplify the boundary conditions for the permit quantity at time $T$ to

$$
X_{i, T}=\left(\int_{0}^{T} Q_{i, s} d s-\delta_{i, T-1}\right)^{+}-\Gamma, \quad \forall \quad i \in I .
$$

Unlike the one-firm model in Section 4.1, this last quantity captures the potential loss implied by the zero-redemption value of unsold permits.

To solve the problem, we consider $\Delta t$ to be the unit time and we discretize the model. Given the initial permit endowments and expectations on the accumulated pollution volumes, each firm minimizes its total costs at every time $t \in[0, T-\Delta t]$. The minimization problem for company $i=1$ at time $T-\Delta t$ is

$$
\min _{\left\{X_{1, T-\Delta t}\right\}}\left\{S_{T-\Delta t} \cdot X_{1, T-\Delta t}+e^{-\eta \Delta t} \mathbb{E}_{\mathbb{P}}\left[S_{T} \cdot X_{1, T} \mid \mathscr{F}_{T-\Delta t}^{1}\right]\right\}
$$

And deriving the FOC:

$$
\begin{aligned}
\bar{S}_{T-\Delta t}= & e^{-\eta \Delta t} \cdot P \cdot \mathbb{E}_{\mathbb{P}}\left[\mathbb{1}_{\int_{0}^{T} Q_{1, s} d s>\delta_{1, T-\Delta t}} \mid \mathscr{F}_{T-\Delta t}^{1}\right] \\
& +e^{-\eta \Delta t} \cdot P \cdot \mathbb{E}_{\mathbb{P}}\left[\mathbb{1}_{\delta_{1, T-\Delta t}>\int_{0}^{T} Q_{1, s} d s} \cdot \mathbb{1}_{\int_{0}^{T} Q_{2, s} d s>\delta_{2, T-\Delta t}} \mid \mathscr{F}_{T-\Delta t}^{1}\right] .
\end{aligned}
$$

Since $\int_{0}^{t} Q_{i, s} d s$ is a monotonically non-decreasing function in $t$, it follows

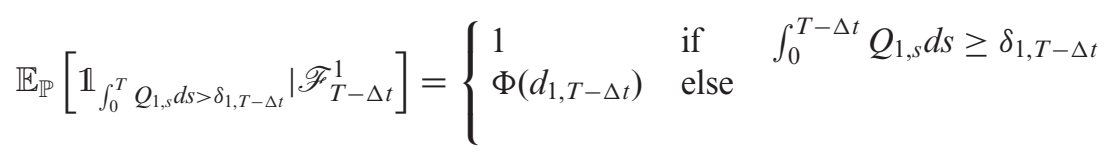

where

$$
d_{1, T-\Delta t}=\frac{\ln \left(\frac{Q_{1, T-\Delta t} \cdot \Delta t}{\delta_{1, T-2 \Delta t}+X_{1, T-\Delta t}-\int_{0}^{T-\Delta t} Q_{1, s} d s}\right)+\left(\mu_{1}-\frac{\sigma_{1}^{2}}{2}\right) \cdot \Delta t}{\sigma_{1} \cdot \sqrt{\Delta t}} .
$$


Let for the moment $L:=\left[\mathbb{1}_{\delta_{1, T-\Delta t}>\int_{0}^{T} Q_{1, s} d s} \cdot \mathbb{1}_{\int_{0}^{T} Q_{2, s} d s>\delta_{2, T-\Delta t}}\right]$, by independence: ${ }^{13}$

$\mathbb{E}_{\mathbb{P}}\left[L \mid \mathscr{F}_{T-\Delta t}^{1}\right]=\left\{\begin{array}{l}0 \quad \text { if } \quad \int_{0}^{T-\Delta t} Q_{1, s} d s \geq \delta_{1, T-\Delta t} \\ \Phi\left(-d_{1, T-\Delta t}\right) \text { if } \int_{0}^{T-\Delta t} Q_{1, s} d s \leq \delta_{1, T-\Delta t} \text { and } \int_{0}^{T-2 \Delta t} Q_{2, s} d s \geq \delta_{2, T-\Delta t} \\ \Phi\left(-d_{1, T-\Delta t}\right) \cdot \Phi\left(d_{2, T-\Delta t}^{\mathrm{lag}}\right) \quad \text { else, }\end{array}\right.$

where

$$
d_{2, T-\Delta t}^{\mathrm{lag}}=\frac{\ln \left(\frac{Q_{2, T-2 \Delta t} \cdot 2 \Delta t}{\delta_{2, T-2 \Delta t}+X_{2, T-\Delta t}-\int_{0}^{T-2 \Delta t} Q_{2, s} d s}\right)+\left(\mu_{2}-\frac{\sigma_{2}^{2}}{2}\right) \cdot 2 \Delta t}{\sigma_{2} \cdot \sqrt{2 \Delta t}} .
$$

Moving on from this, we can then express the price of emission permits analytically for company 1 at time $T-\Delta t$ as the discounted penalty level weighted by the shortage probabilities (for the computations, see Appendix B):

$$
\bar{S}_{T-\Delta t}=e^{-\eta \Delta t} \cdot P \cdot\left[1-\mathcal{P}_{T-\Delta t}^{1}\right]
$$

where

$$
\mathcal{P}_{T-\Delta t}^{1}= \begin{cases}0 \quad \text { if } \quad \int_{0}^{T-\Delta t} Q_{1, s} d s \geq \delta_{1, T-\Delta t} & \text { or } \quad \int_{0}^{T-2 \Delta t} Q_{2, s} d s \geq \delta_{2, T-\Delta t} \\ \Phi\left(-d_{1, T-\Delta t}\right) \cdot \Phi\left(-d_{2, T-\Delta t}^{\mathrm{lag}}\right) & \text { else. }\end{cases}
$$

In other words, $\mathcal{P}_{T-\Delta t}^{1}$ represents the probability of having no future shortfalls for both companies from the point of view of company 1.

Similarly, solving the optimization problem for company 2, it follows:

$$
\bar{S}_{T-\Delta t}=e^{-\eta \Delta t} \cdot P \cdot\left[1-\mathcal{P}_{T-\Delta t}^{2}\right]
$$

where

$$
\mathcal{P}_{T-\Delta t}^{2}= \begin{cases}0 \quad \text { if } \quad \int_{0}^{T-\Delta t} Q_{2, s} d s \geq \delta_{2, T-\Delta t} & \text { or } \quad \int_{0}^{T-2 \Delta t} Q_{1, s} d s \geq \delta_{1, T-\Delta t} \\ \Phi\left(-d_{2, T-\Delta t}\right) \cdot \Phi\left(-d_{1, T-\Delta t}^{\mathrm{lag}}\right) & \text { else. }\end{cases}
$$

Here $d_{2, T-\Delta t}$ and $d_{1, T-\Delta t}^{\text {lag }}$ are defined similarly as above. Also, $\mathcal{P}_{T-\Delta t}^{2}$ represents the probability of having no future shortfalls for both companies from the point of view of company 2. For the sake of simplicity, we use the same discounting factor $\eta$ for both companies. A generalization taking two different discounting factors is straightforward.

Moving backwards and repeating the optimization procedure at each time step $k \in$ $[1,2, \ldots, T / \Delta t]$, we obtain a pair $(i \neq j)$ of emission price equations: 


$$
\bar{S}_{T-k \Delta t}=\left\{\begin{array}{l}
e^{-\eta k \Delta t} \cdot P \quad \text { if } \quad \int_{0}^{T-k \Delta t} Q_{i, s} d s \geq \delta_{i, T-k \Delta t} \text { or } \int_{0}^{T-k \Delta t} Q_{j, s} d s \geq \delta_{j, T-k \Delta t} \\
e^{-\eta k \Delta t} \cdot P \cdot\left\{1-\mathbb{E}_{\mathbb{P}}\left[\Phi\left(-d_{i, T-k \Delta t}\right) \cdot \Phi\left(-d_{j, T-k \Delta t}^{\text {lag }}\right) \mid \mathscr{F}_{T-k \Delta t}^{i}\right]\right\} \text { else. }
\end{array}\right.
$$

At each time step, when the total emissions do not exceed the net amount of permits, we determine the firms' trading decisions by numerically evaluating the quantity of permits that satisfies the following equality:

$$
\mathbb{E}_{\mathbb{P}}\left[\Phi\left(-d_{i, T-\Delta t}\right) \cdot \Phi\left(-d_{j, T-\Delta t}^{\mathrm{lag}}\right) \mid \mathscr{F}_{T-k \Delta t}^{i}\right]=\mathbb{E}_{\mathbb{P}}\left[\Phi\left(-d_{j, T-\Delta t}\right) \cdot \Phi\left(-d_{i, T-\Delta t}^{\mathrm{lag}}\right) \mid \mathscr{F}_{T-k \Delta t}^{j}\right],
$$

for a given set of parameters $\left\{\boldsymbol{\mu}, \boldsymbol{\sigma}, \boldsymbol{Q}_{0}, \boldsymbol{N}_{0}\right\}$ that characterize the two pollution processes. Given firms' trading decisions, the market-clearing condition (6) determines the equilibrium permit price. Equation (13) is derived in Appendix C, where we show that when the total emissions do not exceed the net amount of permits:

$$
\bar{S}_{t}=e^{-\eta \Delta t} \mathbb{E}_{\mathbb{P}}\left[\bar{S}_{t+\Delta t} \mid \mathscr{F}_{t}^{i}\right]=e^{-\eta(T-t)} \mathbb{E}_{\mathbb{P}}\left[\bar{S}_{T} \mid \mathscr{F}_{t}^{i}\right], \quad i \in\{1,2\}
$$

The discounted equilibrium price of emission permits is easily shown to be a martingale with respect to the information set common to the polluters. We formalize this property of the model in the following proposition.

Proposition 1. The discounted equilibrium price process $\left\{\bar{S}_{t}\right\}_{t=0}^{T}$ is a martingale with respect to the information set $\mathscr{F}_{t}$ :

$$
\begin{aligned}
\mathbb{E}_{\mathbb{P}} & {\left[\bar{S}_{T} \mid \mathscr{F}_{t}^{1} \cap \mathscr{F}_{t}^{2}\right] } \\
& =\mathbb{E}_{\mathbb{P}}\left[\mathbb{E}_{\mathbb{P}}\left[\bar{S}_{T} \mid \mathscr{F}_{t}^{1}\right] \mid \mathscr{F}_{t}^{1} \cap \mathscr{F}_{t}^{2}\right] \\
& =\mathbb{E}_{\mathbb{P}}\left[e^{\eta(T-t)} \bar{S}_{t} \mid \mathscr{F}_{t}^{1} \cap \mathscr{F}_{t}^{2}\right]=e^{\eta(T-t)} \bar{S}_{t} .
\end{aligned}
$$

Therefore, the permit price dynamics does not allow for arbitrage opportunities as the model in Seifert et al. (2008).

\subsection{Multi-firm and Multi-periods Trading}

A ready extension of the model to multi-firm is possible splitting the set $\mathscr{I}=$ $\{1,2, \ldots, I\}$ into two parts, $I^{-}:=\mathscr{I}-i$ and $i$, and assuming firm $i$ knows the accumulated pollution level of other firms $I^{-}$in aggregate. Using constant drift and volatility terms, $\left\{\mu \in \mathbb{R}^{I-1}\right.$ and $\left.\sigma \in \mathbb{R}^{+I-1}\right\}$, and relying on standard technique of the methods of moments, one can approximate the cumulative pollution process, $Q_{I^{-}, t}=\sum_{j=1, j \neq i}^{I} Q_{j, t}$, with a new geometric Brownian motion (see Brigo et al. 2004). Along similar lines of Section 4.2, the equilibrium permit price result from the solution of a system of $I$ equations (see Appendix D). We formalize the extension of the model in the following proposition. 
Proposition 2. Given the exogenous pollution processes $Q_{i, u}, u=0, \ldots, t$ for $t=$ $0, \ldots, T-\Delta T$ and company $i=1,2, \ldots I$, the $I$ permit quantities $X_{i, t}$ for $i=$ $1,2, \ldots, I$ and for $j=1,2, \ldots, I, i \neq j$ satisfy the following $\mathrm{I}-1$ equations:

$$
\mathbb{E}_{\mathbb{P}}\left[\mathcal{P}_{t}^{i} \mid \mathscr{F}_{t}^{i}\right]=\mathbb{E}_{\mathbb{P}}\left[\mathcal{P}_{t}^{I^{-}} \mid \mathscr{F}_{t}^{j}\right], \quad \mathscr{I}=I^{-} \cup i
$$

where

$$
\mathcal{P}_{t}= \begin{cases}0 \quad \text { if } \quad \int_{0}^{t} Q_{i, s} d s \geq \delta_{i, t} & \text { or } \quad \int_{0}^{t-\Delta t} Q_{I^{-}, s} d s \geq \delta_{I^{-}, t} \\ \Phi\left(-d_{i, t}\right) \cdot \Phi\left(-d_{I^{-}, t}^{\text {lag }}\right) & \text { else, }\end{cases}
$$

and the market-clearing condition $\sum_{i=1}^{I} \bar{X}_{i, t}=0$ for all $t=0, \ldots, T-\Delta t$.

The price process $\bar{S}=\left\{\bar{S}_{t}\right\}_{t=0}^{T}$ uniquely defined as

$$
\bar{S}_{t}=e^{-\eta(T-t)} \cdot P \cdot\left\{1-\mathbb{E}_{\mathbb{P}}\left[\mathcal{P}_{t}^{i} \mid \mathscr{F}_{t}^{i}\right]\right\}
$$

is the equilibrium permit price process.

It is remarkable to notice that, at each time step, both the permits traded-quantity and the permit price, in equilibrium, are the result of the companies' dynamic adjusting of emission portfolio allocations based on the accumulated pollution processes and the available information about net permit positions. In Section 5, we delve deeper into these aspects by means of an extensive numerical exercise.

\section{Numerical Evaluation}

For illustrative purposes we consider $I=2$. Based on Equation (14) and the marketclearing condition (6), we simulate several paths of the emission permit price. In each simulation exercise, we purposely choose $N_{i} \approx Q_{i, 0} \cdot \int_{0}^{T} e^{\mu_{i} t} d t$. Also, the time period $T$ is fixed at 1 year (i.e. 250 trading days, $\Delta t$ ), the weighted average cost of capital is set at $10 \%$ and the penalty, $P$, is equal to 40 .

Starting at $t=0$, and using Equation (1), we simulate a pair of independent pollution processes: one for each company $i, i \in I$. Then, each firm chooses the optimal number of permits to buy or to sell. Solving Equation (14) coupled with the marketclearing condition (6), we (numerically) determine the permit quantities and, using Equation (13), the equilibrium permit price $S_{0}^{1}$. This procedure is repeated $n$-times to evaluate the expected equilibrium permit price $\bar{S}_{0}:=\sum_{j=1}^{n} S_{0}^{j} / n$. At time $t=\Delta t$, the resulting net-permits positions $\left(\delta_{i, 0} ; i=1,2\right)$ are evaluated using $\bar{S}_{0}$ and a fixed pair of accumulated pollution volumes, randomly chosen among the $n$ pairs of pollution simulations. Repeating $n$-times the procedure described above, we compute the expected equilibrium permit price $\bar{S}_{\Delta t}$. Reiterating this at each time step up to $T-\Delta t$, we obtain the simulated equilibrium permit price history depicted in the bottom diagram Figure 3.

Figures 3 and 4 illustrate the equilibrium permit price evolution stopped at three different time steps (50,150 and 200 days) of the described procedure. In particular, the 

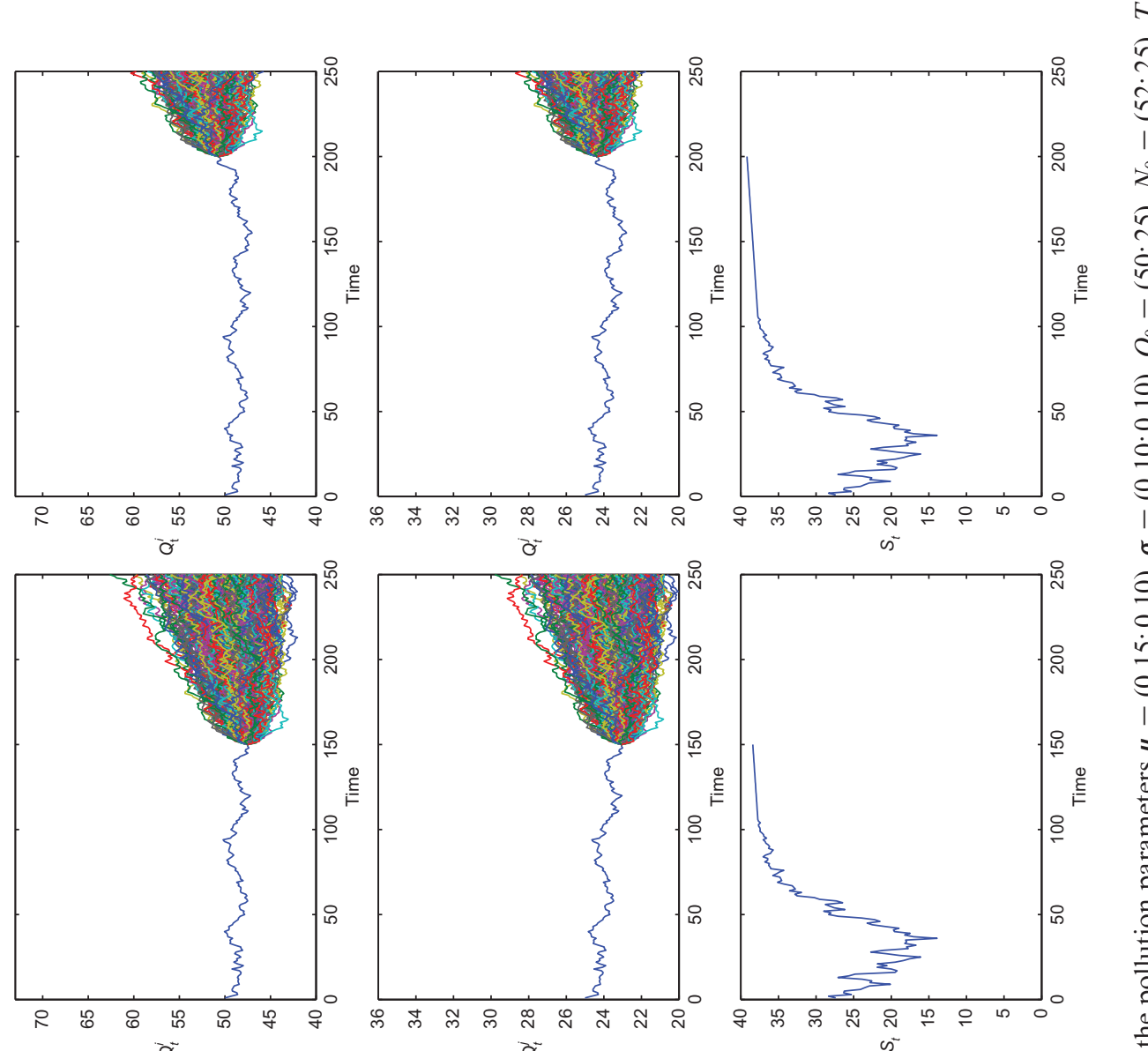

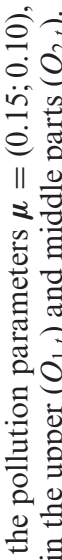
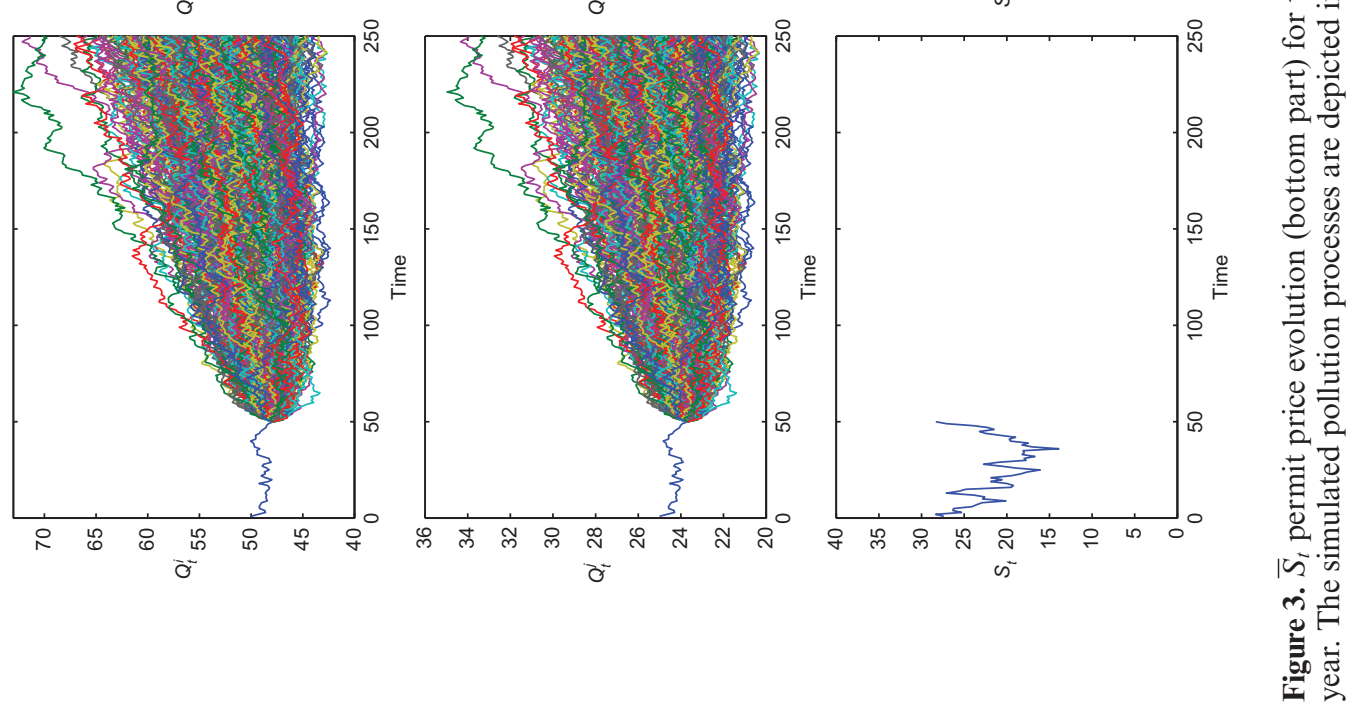


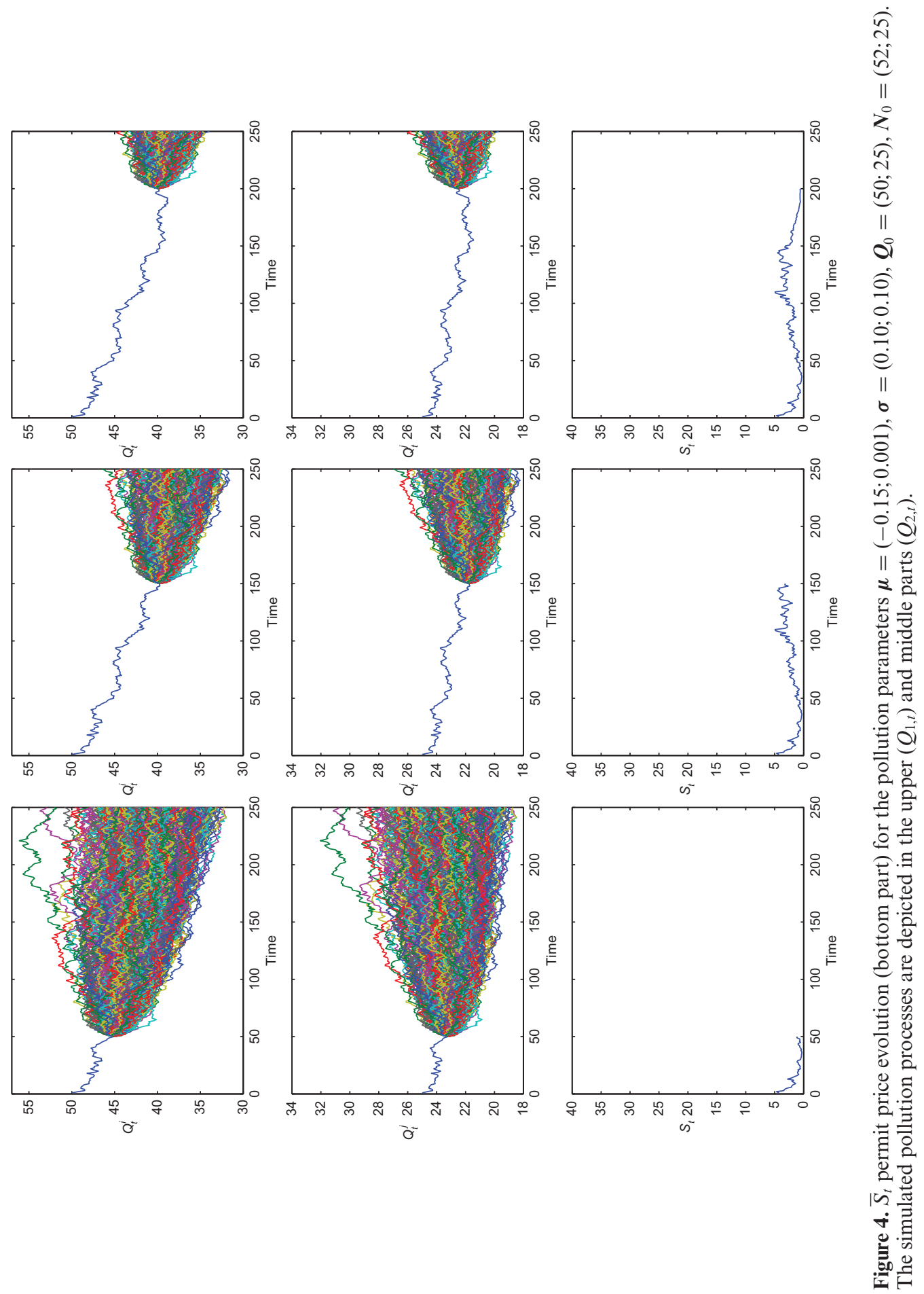


upper two diagrams show many possible paths of the pollution process after 50,150 and 200 days. The bottom diagram shows the equilibrium permit price path conditioned on the information sets $\mathscr{F}_{50}, \mathscr{F}_{150}$ and $\mathscr{F}_{200}$, respectively. Figure 3 depicts a situation where both companies' pollution processes have a positive quick-paced drift of $15 \%$ and $10 \%$, respectively, and a mild volatility level, set at $10 \%$ for both. While the second firm has been equipped with an initial permit endowment approximately equal to its expected pollution level, $Q_{2,0} \cdot \int_{0}^{T} e^{\mu_{2} t} d t$, the first firm has been allocated an initial amount of permits slightly smaller than $Q_{1,0} \cdot \int_{0}^{T} e^{\mu_{1} t} d t$. As observable in the bottom diagram of Figure 3, the relative scarcity of permits becomes clear as time goes by and uncertainty is resolved. Modifying the pollution drift terms and setting, respectively, a negative value for the first firm, $\mu_{1}=-0.15$, and a negligible drift term for the second one, $\mu_{2}=0.001$, we observe a reverse effect, other things being equal. The bottom diagram of Figure 4 shows that the combination of initial amount of permits chosen, $\mathbf{N}_{0}=(52 ; 25)$, and a negative drift result in a low price.

Figure 5 depicts a brief sensitivity analysis of the equilibrium permit price with respect to the parameters of the companies' pollution processes. Starting from a set of conveniently chosen parameters, that is $\boldsymbol{\mu}=(0.25 ; 0.20), \sigma=(0.15 ; 0.40), \boldsymbol{Q}_{0}=$ $(50 ; 25), N_{0}=(60 ; 40)$, we let the drift and volatility terms of company 1 vary, both in the first and in the second picture, keeping all the other parameters constant. As expected, the larger $\mu_{1}$ is, the higher is the probability of being in shortage by the end of the period, i.e. $T$. This reasonably implies an upward trend in the permit price. As time moves forward and uncertainty is resolved, the initial permit endowments are sufficiently large to lead to a price decrease (Figure $5 a$ ). However, in the particular simulated exercise, it appears that the price increases (to 40) in three of the cases, and decreases (to 0 ) in the other three.

Similarly, the larger $\sigma_{1}$ is, the higher is the uncertainty about $\int_{t}^{T} Q_{1, s} d s-\delta_{1, T-\Delta t}$, i.e. the net permit position before the compliance date, and consequently about the probability of having no future shortfalls for both companies, i.e. $\mathcal{P}_{t}^{i}, t \in[0, T-\Delta t]$. As can be observed, a volatility increase does not necessarily increases the permit price. When there is no clear permit shortage, higher volatility uncertainty is reflected in a higher permit price. Conversely, the permit price is simply equal to the discounted penalty level. In our particular simulated example, while more information about the accumulated pollution volumes is collected, the current permit amount value takes precedence over the overall uncertainty level. This, in turn, leads to a price decrease (Figure $5 b$ ). Finally, the impact of different pairs of initial permit endowments is observable (Figure $5 c$ ). The upper line depicts a clear shortage situation. After some trading time, the shortage status becomes a fact and the permit price is simply the discounted penalty level. The lower line depicts the opposite situation. Both companies have been allocated an amount of permits that is over-generous and the permit price hovers slightly above zero (Figure $5 c$ ). It is extremely interesting to observe that the middle dashed-price path very closely resembles the empirical spot permit price of $\mathrm{CO}_{2}$ in the European market during 2005-2007. After a period of slow but continuous upward movement, due to purchasers being convinced of a shortage, the price plummeted by almost $70 \%$ in almost one day, thereafter drifting towards 0 . This price reverse can be attributed to the disappearance of asymmetric information among market players in terms of their net permits positions. By the end of 2007, the emission 
(a)

Price simulaton for different $\mu_{1}$

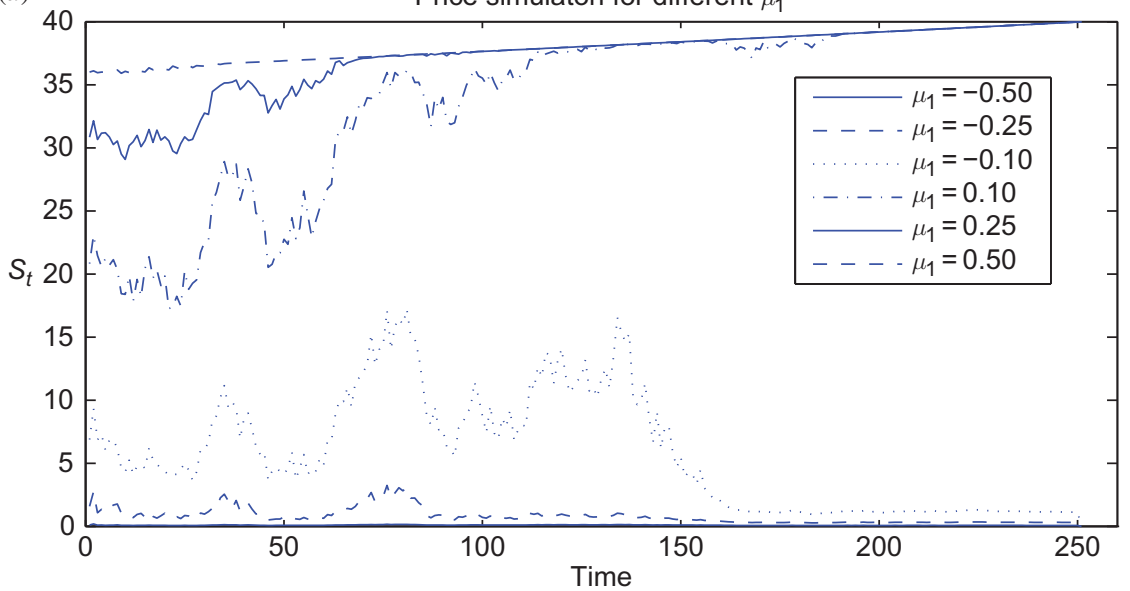

(b)

Price simulaton for different $\sigma_{1}$

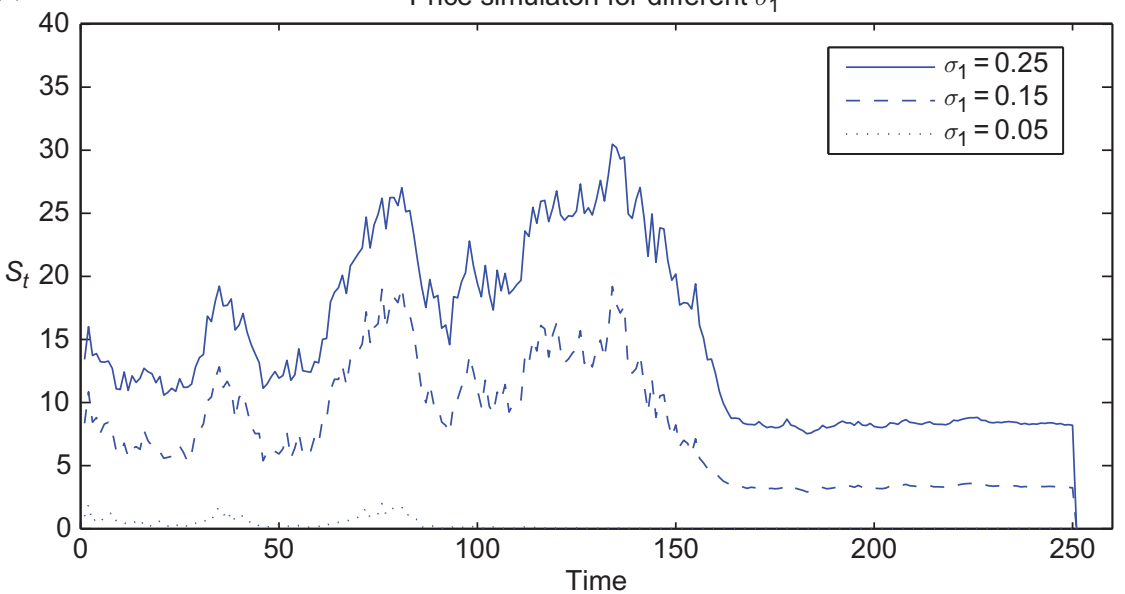

(c)

Price simulaton for different $N_{0}$

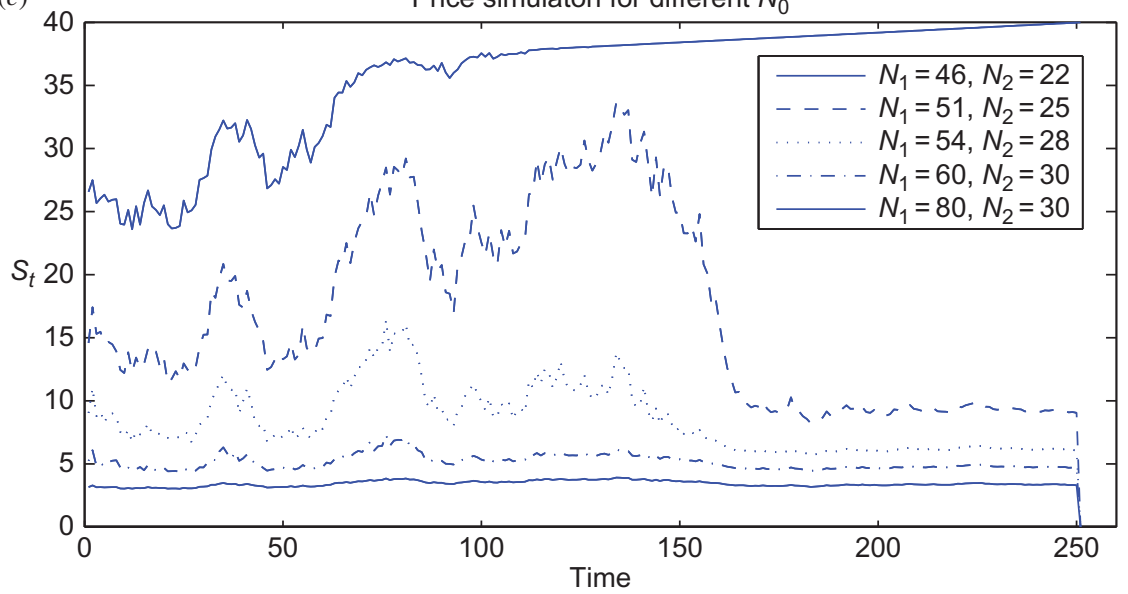

Figure 5. $\bar{S}_{t}$ permit price evolution letting vary the drift and the volatility terms for company $1,(a)$ and $(b)$, and both the initial permits endowments (c). When not otherwise specified in the legend, parameter used in the numerical exercise are $\mu=[-0.15 ; 0.001], \sigma=[0.10 ; 0.10]$, $Q_{0}=[50 ; 25], N_{0}=[52 ; 25]$. 


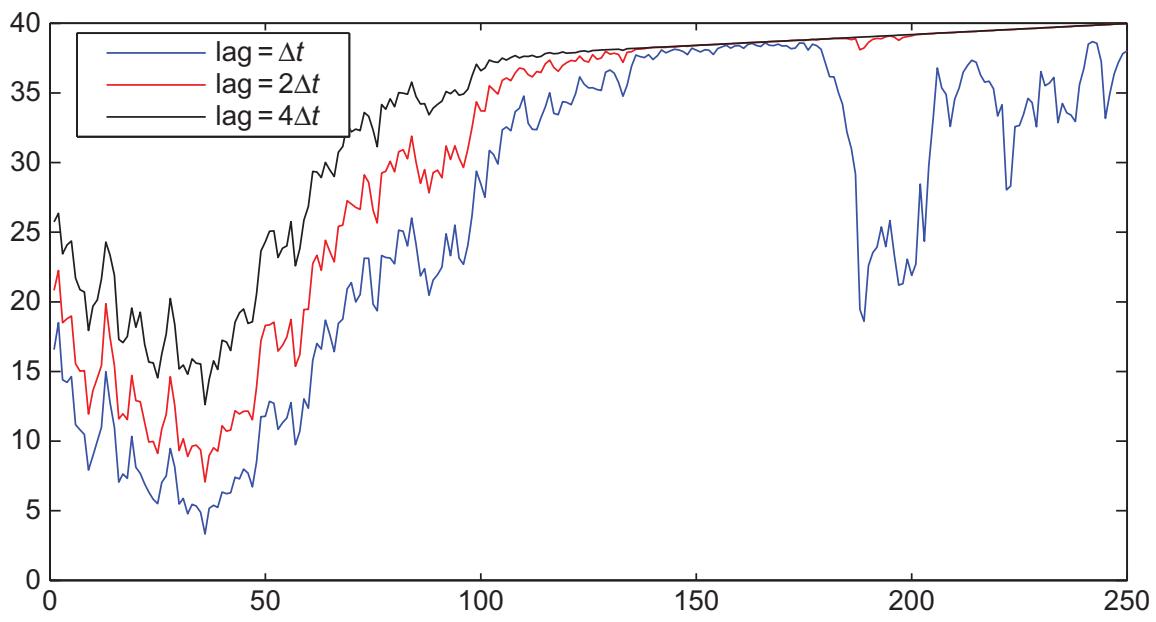

Figure 6. $\bar{S}_{t}$ permit price evolution letting vary the length of the lags, lag $=[\Delta t, 2 \Delta t, 4 \Delta t]$. The parameter used in the numerical exercise are $\boldsymbol{\mu}=[0.05 ; 0.001], \boldsymbol{\sigma}=[0.10 ; 0.10], \boldsymbol{Q}_{0}=[50 ; 25]$, $\boldsymbol{N}_{0}=[52 ; 25]$.

permit spot price for phase I is almost nil; however, it would have been zero only if the probability of an excess situation had been exactly one. This feature, along with the described price reaction to drift and volatility movement, is common to standard financial option contracts. Finally, it is interesting to observe which is the impact of a longer length of the information lag. In particular, we tested the situation where the length of the information lags is two-time $(2 \Delta t)$ and four-time longer $(4 \Delta t)$ than the previous examples. Figure 6 shows the impact we observe on the price paths caused by varying the lag. The result is consistent with what we would expect: shortening the lag causes the uncertainty about the net permit position to be resolved earlier.

\section{Application to Option Pricing}

A $\mathrm{CO}_{2}$ option market is slowly growing and attracting a wide variety of industrials, utilities and financial institutions of various nature. The importance of such a market is two-fold. First, $\mathrm{CO}_{2}$ option contracts satisfy the primary need of risk transfer from those who wish to reduce the risk of a permit shortage situation, namely the risk of financial exposure, to those willing to accept it. By allowing European covered companies to reduce their exposure to price risk, buyers and sellers can better plan their businesses. Furthermore, any project-based investment, that is investments committed under the so-called CDM and JI mechanisms, which at regular intervals returns $\mathrm{CO}_{2}$ emission reduction certificates yielding a pay-off that depends on the $\mathrm{CO}_{2}$ permit market price, can be considered as (real) option contracts. It is natural to interpret such projects as contracts whose value derives from the future $\mathrm{CO}_{2}$ spot permit price. Similarly, any technological abatement investment or production process modification can be valued in terms of saved costs from purchasing emission permits or revenue from the sales of extra unused permits. As mentioned in Section 3, Chao and Wilson (1993) used this argument in order to identify a plausible reason for the difference between the marginal cost of running abatement technologies such as scrubbers and 
the emission allowance price. They called this difference the option premium. This is the first article that discovers the option-value implicitly embedded in the value of an emission permit. In line with this consideration, an option where the underlying is any sort of tradable permit is in fact a compound option.

In this section, we propose a closed-form pricing formula for European-style options. Let us construct two portfolios at time $t$. The first one is a European Call option with a pay-off $\left(S_{T}-K\right)^{+}$at maturity, the second one corresponds to $(P-K) / P$ units of emission permits. According to our model, at time $T$ there are only two possible states for the price of emission permits $S_{T}$, i.e. $\{0, P\}$, therefore both portfolios generate the same profit at maturity:

$$
\begin{cases}P-K, & \text { if } \quad S_{T}=P \\ 0, & \text { if } \quad S_{T}=0 .\end{cases}
$$

In the absence of arbitrage opportunities, the two portfolios must have the same price at initial time. Therefore, the following option pricing formula is obtained:

$$
C_{E}(t)=\frac{P-K}{P} \cdot S_{t}
$$

where $C_{E}(t)$ is the Call price at time $t, t<T$. Similarly, let us consider a new portfolio long in a European Put with pay-off at maturity $\left(K-S_{T}\right)^{+}$and short in one risk-less bond that generates a pay-off equal to the strike price $K$ at maturity $T$. This portfolio has the following final pay-off at time $T$ :

$$
\left\{\begin{array}{lll}
-K & \text { if } & S_{T}=P \\
0 & \text { if } & S_{T}=0 .
\end{array}\right.
$$

A portfolio long in a European Call $C_{E}$ and short in one emission permit generates the same pay-off as in (19).

The absence of arbitrage opportunities generates then the following option-pricing formula for the European Put $P_{E}(t)$ :

$$
\begin{aligned}
P_{E}(t) & =e^{-r(T-t)} \cdot K+C_{E}(t)-S_{t} \\
& =K \cdot\left(e^{-r(T-t)}-\frac{S_{t}}{P}\right),
\end{aligned}
$$

where $r$ is the risk-free interest rate. Obviously, the right-hand side of Equation (20) is positive because, as shown previously, the upper bound of the price of emission permits is the discounted penalty. Equation (20) corresponds to the Put-Call parity.

Although options traded on exchanges like the European Climate Exchange are generally options on forwards, we tested the validity of this formula pricing call and put options with maturity December 2007. The empirical performance of the closed-form formula relative to the well-known Black-Scholes-Merton formula is encouraging. 
Results are available from the authors upon request. Although we reckon that this pricing formula is affected by the model assumption and that its utility is rather limited for option-pricing purposes, we believe that it expresses an interesting relationship.

\section{Conclusion}

Distinguishing between pollution abatement policies in the short and long term for those companies covered by market-based environmental regulations, we model the endogenous price dynamics of marketable permits under asymmetric information, allowing banking and borrowing, in a two-firms multi-period setting. We extend the model to more than two firms. Each firm's pollution emission follows an exogenously given stochastic process. At maturity, firms try to reconcile their permit holding with the accumulated emissions: if a firm's permit holding is less than its accumulated pollution, it has to pay a penalty for each permit in shortage at a pre-determined rate. The optimization problem of each firm and the market-clearing condition in each period determine the traded permit quantities and the equilibrium permit price. In the article, we prove that the price path of emission permits depends on the future probability of a shortfall in permits, the penalty that will be paid in the event of a shortfall, and the discount rate. The model is solved numerically in in the two-firms multi-period setting, and statistical features are discussed. Finally, we derive and discuss a closed-form pricing formula for European-style options based on the equilibrium model proposed.

\section{Acknowledgements}

The authors thank Pauline Barrieu, Federica Buricco, Ivar Ekeland, Rajna Gibson, Juri Hinz, Michael Kupper, Ashkan Nikeghbali, Urs Schweri, Daniel Sztutwojner, Alexander Wagner and participants of the workshop 'Mathematics and the Environment: Energy Risk, Environmental Uncertainty and Public Decision Making' (Banff - Canada), of the 'IX Workshop on Quantitative Finance' (Rome - Italy), and of the '8th Ritsumeikan International Symposium on Stochastic Processes and Application to Mathematical Finance - 8th Columbia Jafee Conference' (Kyoto Japan) for their helpful discussions and comments. Part of Chesneys research was supported by the University Research Priority Program Finance and Financial Markets and by the National Centre of Competence in Research Financial Valuation and Risk Management (NCCR FINRISK), research instruments of the University of Zürich and the Swiss National Science Foundation, respectively. Taschini gratefully acknowledges financial support from the Centre for Climate Change Economics and Policy, which is funded by the UK Economic and Social Research Council (ESRC) and Munich Re. The usual disclaimers apply.

\footnotetext{
Notes

${ }^{1}$ The theory of emissions trading and the economic benefit over traditional command-and-control approaches to environmental regulation are discussed in detail by Baumol and Oates (1988) and Tietenberg (1985).

${ }^{2}$ It involves the replacement of high-carbon (sulfur) fuels with low-carbon (sulfur) alternatives. The most common form of fuel switching in the United States is the replacement of high-sulfur coal with a low-sulfur coal. In Europe, coal is typically replaced with natural gas.
} 
${ }^{3}$ Hedging strategies can be constructed by means of futures contracts or by introducing option instruments (the first option contract on $\mathrm{CO}_{2}$ was traded in October 2005 between the French electricity company EDF and the Amsterdam-based company Statkraft). Futures are traded both over-the-counter (OTC) and on several exchanges.

${ }^{4}$ According to environmental terminology, spatial trading means that a unit can reduce its emissions below its allocated number of allowances, transferring its unused permits to other units within the same company or selling them to other companies or brokers. Conversely, it can decide not to abate its emissions but to purchase allowances covering emissions above its allocation.

${ }^{5}$ It should be understood that the equality between permit price and marginal abatement costs breaks down as soon as the excess of the permit supply over the expected accumulated pollution is evident, as shown in the numerical solution part of the article.

${ }^{6}$ It is important to note that currently there is no commercially available end-of-the-stack technology to extract carbon dioxide.

${ }^{7}$ In Fehr and Hinz (2006), the coincidence of the equilibrium permit price with the resolution of social planner problem is a result of the model since fuel-switching is considered as a perfect substitute of emission permits.

${ }^{8}$ The measure $\mathbb{P}$ refers to the historical probability. We refer to Carmona and Hinz (2011) for a discussion and evaluation of the risk neutral pollution dynamics under an equivalent measure $\mathbb{Q}$.

${ }^{9}$ It is worth noting that Equation (5) corresponds to the equilibrium permit price described in theorem 1 of Fehr and Hinz (2006).

${ }^{10} \mathrm{An}$ analysis of the interests of the various players in the market (governments, financial institutions, industrials and energy companies and NGOs) might lead to a different interpretation of permit price dynamics in the EU ETS. For instance, one might investigate the case where players can take a speculative approach by selling off permits when the allowance price is high, and purchasing them back later on if in a permit need situation or if the permit price is conveniently low. The study of their impact on the emission market is left for future research.

${ }^{11}$ Section 6 briefly describes these certificates.

${ }^{12}$ This is an assumption we required for model tractability. However, from a practical point of view, the EU ETS covers five different industrial sectors and almost 11.500 installations in 27 European countries. So, it is plausible that two companies, although belonging to the same industrial sector, are affected by different technical, commercial and operational factors.

${ }^{13}$ We described above the practical implications of this mathematical simplification.

${ }^{14}$ The particular feedback effect has been captured through BSDEs when modelling the energy production sector - see the work by Schwarz and Howison (2010) and Carmona et al. (2010).

\section{References}

Bahn, O., Büler, B., Kypreos, S. and Lüthi, H. J. (1999) Modelling an international market of $\mathrm{CO}_{2}$ emission permits, International Journal of Global Energy Issues, 12(5), pp. 283-291.

Baumol, W. J. and Oates, W. E. (1988) The Theory of Environmental Policy (Cambridge: Cambridge University Press).

Benz, E. and Trück, S. (2009) Modeling the price dynamics of $\mathrm{CO}_{2}$ emission allowances, Energy Economics, 31(1), pp. 4-15.

Brigo, D., Mercurio, F., Rapisarda, F. and Scotti, R. (2004) Approximated moment-matching dynamics for basket-options simulation, Quantitative Finance, 4(1), pp. 1-16.

Carmona, R., Delarue, F., Gilles-Edouard, E. and Touzi, N. (2010) Singular forward-backward stochastic differential equations and emissions derivatives. Working Paper HAL 00555591 Ecole Politechnique. Available at http://hal-unice.archives-ouvertes.fr/hal-00555591_v2/ (accessed 1 Dec 2011).

Carmona, R. and Hinz, J. (2011) Risk-neutral modeling of emission allowance prices and option valuation, Management Science, 57(8), pp. 1453-1488.

Chao, H. and Wilson, R. (1993) Option value of emission allowances, Journal of Regulatory Economics, 5(3), pp. 233-249.

Coase, R. (1960) The problem of social cost, Journal of Law and Economics, 3(1), pp. 1-44. 


\section{M. Chesney and L. Taschini}

Cronshaw, M. B. and Kruse, J. B. (1996) Regulated firms in pollution permit markets with banking, Journal of Regulatory Economics, 9(2), pp. 179-189.

Dales, J. (1968) Pollution Property and Prices (Toronto, ON: University of Toronto Press).

Daskalakis, G., Psychoyios, D. and Markellos, R. (2009) Modeling $\mathrm{CO}_{2}$ emission allowance prices and derivatives: evidence from the european trading scheme, Journal of Banking and Finance, 33(17), pp. $1230-1241$.

Farzin, Y. H. and Kort, P. M. (2000) Pollution abatement investment when environmental regulation is uncertain, Journal of Public Economic Theory, 2(2), pp. 183-212.

Fehr, M. and Hinz, J. (2006) A Quantitative Approach to Carbon Price Risk Modeling (Zurich: Institute of Operations Research, ETH).

Geman, H. and Yor, M. (1993) Bessel processes, asian options, and perpetuities, Mathematical Finance, 3(4), pp. 349-375.

Hidalgo, I., Szabö, L., Ciscar, J. C. and Soria, A. (2005) Technological prospects and $\mathrm{CO}_{2}$ emission trading analysis in the iron and steel industry: a global model, Energy, 30(5), pp. 583-610.

Insley, M. C. (2003) On the option to invest in pollution control under a regime of tradable emission allowances, Canadian Journal of Economics, 36(4), pp. 860-883.

Montgomery, W. (1972) Markets in licenses and efficient pollution control programs, Journal of Economic Theory, 5(3), pp. 395-418.

Paolella, M. S. and Taschini, L. (2008) An econometric analysis of emission-allowances prices, Journal of Banking and Finance, 32(10), pp. 2022-2032.

Pigou, A. (1918) The Economics of Welfare (London: Macmillan Press).

Rubin, J. D. (1996) A model of intertemporal emission trading, banking, and borrowing, Journal of Environmental Economics and Management, 31(3), pp. 269-286.

Schennach, S. M. (2000) The economics of pollution permit banking in the context of Title IV of the 1990 Clean Air Act Amendments, Journal of Environmental Economics and Management, 40(3), pp. 189-210.

Schwarz, D. and Howison, S. (2010) Risk-Neutral Pricing of Financial Instruments in Emission Markets (Oxford: Mathematical Institute, University of Oxford).

Seifert, J., Uhrig-Homburg, M. and Wagner, M. (2008) Dynamic behavior of $\mathrm{CO}_{2}$ spot prices, Journal of Environmental Economics and Managements, 56(2), pp. 180-194.

Szabö, L., Hidalgo, I., Ciscar, J. C. and Soria, A. (2006) $\mathrm{CO}_{2}$ emission trading within the European Union and Annex B countries: the cement industry case, Energy Policy, 34(1), pp. 72-87.

Taschini, L. (2010) Environmental economics and modeling marketable permits, Asian Pacific Financial Markets, 17(4), pp. 325-343.

Tietenberg, T. (1985) Emission trading: an exercise in reforming pollution policy. Working Paper, Resources for the Future, Washington, DC.

Zhao, J. (2003) Irreversible abatement investment under cost uncertainties: tradable emission permits and emissions charges, Journal of Public Economics, 87(12), pp. 2765-2789.

\section{Appendix A}

The following objective function has to be minimized with respect to $X_{0}$

$$
\mathrm{H} \equiv\left\{S_{0} \cdot X_{0}+e^{-\eta T} \mathbb{E}_{\mathbb{P}}\left[\left(\frac{4}{\sigma^{2}} \cdot Q_{0} \cdot A_{\sigma^{2} T / 4}^{z}-N_{0}-X_{0}\right)^{+} \cdot P\right]\right\}
$$

and denoting $A_{T}^{v}=\int_{0}^{T} e^{2\left(W_{s}+v s\right)} d s, \quad v:=\frac{1}{\sigma} \cdot\left(\mu-\frac{\sigma^{2}}{2}\right)$.

The law of $A_{t}^{z} \quad$ is $\mathbb{P}\left(A_{t}^{z} \in d x\right)=\varphi(t, x) d x$, where $z:=\frac{2 v}{\sigma}$,

$$
\varphi(t, x)=x^{\nu-1} \frac{1}{\left(2 \pi^{3} t\right)^{1 / 2}} e^{\left(\frac{\pi^{2}}{2 t}-\frac{1}{2 x}-\frac{\nu^{2} t}{2}\right)} \int_{0}^{\infty} y^{\nu} e^{-\frac{1}{2} x y^{2}} \Upsilon_{y}(t) d y
$$




$$
\Upsilon_{r}(t)=\int_{0}^{\infty} e^{-\frac{y^{2}}{2 t}} \cdot e^{-r(\cosh y)} \cdot \sinh (y) \cdot \sin \left(\frac{\pi y}{t}\right) d y .
$$

Computing the FOC the following is obtained:

$$
\bar{S}_{0}=e^{-\eta T} \cdot P \cdot \mathbb{P}\left[A_{\sigma^{2} T / 4}^{z}>\frac{\delta_{0} \cdot \sigma^{2}}{4 Q_{0}}\right]
$$

Therefore, we can express the emission allowance price as a function of the penalty and the probability of permit shortage:

$$
\bar{S}_{0}=e^{-\eta T} \cdot P \cdot \int_{\delta_{0} \cdot \sigma^{2} / 4 Q_{0}}^{\infty} \mathbb{P}\left[A_{\sigma^{2} T / 4}^{z} \in d x\right] .
$$

For a simple analytical interpretation of the problem we can assume $T=\Delta t$, where $\Delta t$ is a small time interval, and approximate the cumulative pollution process with its discrete representation:

$$
\int_{0}^{T} Q_{s} d s=Q_{0} e^{\left(\mu-\frac{\sigma^{2}}{2}\right) \Delta t+\sigma W_{\Delta t}} \cdot \Delta t
$$

Substituting in the objective function it follows:

$$
\mathrm{H} \equiv\left\{S_{0} \cdot X_{0}+e^{-\eta T} \mathbb{E}_{\mathbb{P}}\left[\left(Q_{0} e^{\left(\mu-\frac{\sigma^{2}}{2}\right) \Delta t+\sigma W_{\Delta t}} \cdot \Delta t-N_{0}-X_{0}\right)^{+} \cdot P\right]\right\} .
$$

Computing the FOC it follows:

$$
\begin{aligned}
\bar{S}_{0} & =e^{-\eta T} \cdot P \cdot \mathbb{E}_{\mathbb{P}}\left[\begin{array}{l}
\mathbb{1} Q_{0} e^{\left(\mu-\frac{\sigma^{2}}{2}\right) \Delta t+\sigma W_{\Delta t}} \cdot \Delta t>N_{0}+X_{0}
\end{array}\right] \\
& =e^{-\eta T} \cdot P \cdot \mathbb{P}\left[Q_{0} e^{\left(\mu-\frac{\sigma^{2}}{2}\right) \Delta t+\sigma W_{\Delta t}} \cdot \Delta t>N_{0}+X_{0}\right],
\end{aligned}
$$

moving on from this, we express the price as a function of the penalty and the probability of permit shortage and the results of Equation (5) are obtained.

\section{Appendix B}

The following objective function has to be minimized with respect to $X_{1, T-\Delta t}$ :

$$
H \equiv\left\{S_{T-\Delta t} \cdot X_{1, T-\Delta t}+e^{-\eta \Delta t} \mathbb{E}_{\mathbb{P}}\left[S_{T} \cdot X_{1, T} \mid \mathscr{F}_{T-\Delta t}^{1}\right]\right\} .
$$

Deriving the FOCs, we arrive at Equation (10). To explicitly model the presence of asymmetric information regarding emission levels as explained in Section 4.2, we consider the discrete approximation for the pollution processes and obtain 


$$
\begin{aligned}
\mathbb{P}\left(\int_{0}^{T} Q_{1, s} d s>\delta_{1, T-\Delta t}\right) & =\mathbb{P}\left(Q_{1, T-\Delta t} \cdot e^{\left(\mu_{1}-\frac{\sigma_{1}^{2}}{2}\right) \cdot \Delta t+\sigma_{1} W_{\Delta t}} \cdot \Delta t>\delta_{1, T-\Delta t}-\int_{0}^{T-\Delta t} Q_{1, s} d s\right) \\
& =\Phi\left(d_{1, T-\Delta t}\right),
\end{aligned}
$$

where $d_{1, T-\Delta t}$ is defined in Section 4.2. Similarly

$$
\mathbb{E}_{\mathbb{P}}\left[\mathbb{1}_{\delta_{1, T-\Delta t}>\int_{0}^{T} Q_{1, s} d s} \mid \mathscr{F}_{T-\Delta t}^{1}\right]=\left\{\begin{array}{ll}
0 & \text { if } \\
\Phi\left(-d_{1, T-\Delta t}\right) & \text { else }
\end{array} \int_{0}^{T-\Delta t} Q_{1, s} d s \geq \delta_{1, T-\Delta t}\right.
$$

and

$$
\mathbb{E}_{\mathbb{P}}\left[\mathbb{1}_{\int_{0}^{T} Q_{2, s} d s>\delta_{2, T-\Delta t}} \mid \mathscr{F}_{T-\Delta t}^{1}\right]=\left\{\begin{array}{ll}
1 & \text { if } \quad \int_{0}^{T-2 \Delta t} Q_{2, s} d s \geq \delta_{2, T-\Delta t} \\
\Phi\left(d_{2, T-\Delta t}^{\text {lag }}\right) & \text { else }
\end{array},\right.
$$

where $d_{2, T-\Delta t}^{\text {lag }}$ is defined in Section 4.2. Noting that

$$
\Phi\left(d_{1, T-\Delta t}\right)+\Phi\left(-d_{1, T-\Delta t}\right) \cdot \Phi\left(d_{2, T-\Delta t}^{\mathrm{lag}}\right)=1-\Phi\left(-d_{1, T-\Delta t}\right) \cdot \Phi\left(-d_{2, T-\Delta t}^{\mathrm{lag}}\right),
$$

and letting $\mathcal{P}_{T-\Delta t}^{1}:=\Phi\left(-d_{1, T-\Delta t}\right) \cdot \Phi\left(-d_{2, T-\Delta t}^{\text {lag }}\right)$, it follows that

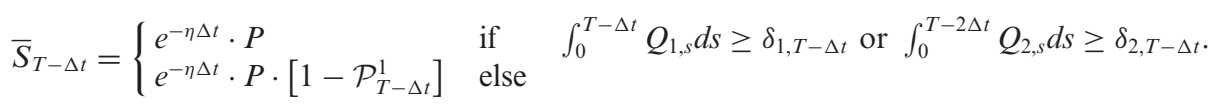

The same computation holds for Equation (12).

\section{Appendix C}

The following objective function has to be minimized with respect to $X_{1, T-2 \Delta t}$ :

$$
H \equiv\left\{S_{T-2 \Delta t} \cdot X_{1, T-2 \Delta t}+e^{-\eta \Delta t} \mathbb{E}_{\mathbb{P}}\left[\bar{S}_{T-\Delta t} \cdot \bar{X}_{1, T-\Delta t}+e^{-\eta \Delta t} \cdot S_{T} \cdot X_{1, T} \mid \mathscr{F}_{T-2 \Delta t}^{1}\right]\right\} .
$$

Computing the FOC, the following is obtained:

$$
0=S_{T-2 \Delta t}+e^{-\eta \Delta t} \mathbb{E}_{\mathbb{P}}\left[\bar{S}_{T-\Delta t} \cdot \frac{\partial \bar{X}_{1, T-\Delta t}}{\partial X_{1, T-2 \Delta t}}+\bar{X}_{1, T-\Delta t} \cdot \frac{\partial \bar{S}_{T-\Delta t}}{\partial X_{1, T-2 \Delta t}}\right]
$$

because by Equation (7), $S_{T}=\{0, P\}$, hence $X_{1, T} \cdot \frac{\partial S_{T}}{\partial X_{1, T-2 \Delta t}}=0$.

Moreover, considering the existence of a lag-effect due to the presence of asymmetric information and assuming that

$$
\frac{\partial \bar{X}_{1, T-(j-1) \Delta t}}{\partial X_{1, T-j \Delta t}}=-1, \quad \frac{\partial \bar{X}_{1, T-(j-k) \Delta t}}{\partial X_{1, T-j \Delta t}}=0 \quad \text { where } \quad k \in[2, j] \quad k \in \mathbb{N}
$$


it follows

$$
\frac{\partial \bar{X}_{1, T}}{\partial X_{1, T-2 \Delta t}}=0 .
$$

The previous assumptions are introduced for the sake of tractability of the model. A rigorous mathematical approach requires the introduction of backward-forward stochastic differential equations (BFSDEs) in order to model the decision problem. ${ }^{14}$ In fact, it is not sufficient to solve a stochastic dynamic programming problem since at each time step $(T-j \Delta t)$ the control variable (the quantity of permits to buy or to sell) is a function of the previous quantity of permits traded $((T-(j+h) \Delta t)$, where $h \in[1, T / \Delta t-j] \quad h \in \mathbb{N})$ and of the future quantity of permits that will be traded $((T-(j-k) \Delta t)$, where $k \in[1, j] \quad k \in \mathbb{N})$.

Let us define

$$
a_{1}=\left(\delta_{1, T-2 \Delta t}+\bar{X}_{1, T-\Delta t}-\int_{0}^{T-\Delta t} Q_{1, s} d s\right), b_{2}^{\operatorname{lag}}=\left(\delta_{2, T-2 \Delta t}+\bar{X}_{2, T-\Delta t}-\int_{0}^{T-2 \Delta t} Q_{2, s} d s\right),
$$

since $X_{1, s}=-X_{2, s} \quad \forall s \in[0, T-1]$. Let us first consider the case where the total emissions, $\int_{0}^{T-2 \Delta t} Q_{1, s} d s$, are below the net amount of permits, $\delta_{1, T-2 \Delta t}$. Contingent on this condition, and recalling Equation (11), we can expand $\partial \bar{S}_{T-\Delta t} / \partial X_{1, T-2 \Delta t}$ as follows:

$$
\begin{aligned}
\frac{\partial \bar{S}_{T-\Delta t}}{\partial X_{1, T-2 \Delta t}} & =\frac{\partial}{\partial X_{1, T-2 \Delta t}}\left[e^{-\eta \Delta t} \cdot P\left[1-\Phi\left(-d_{1, T-\Delta t}\right) \cdot \Phi\left(-d_{2, T-\Delta t}^{\mathrm{lag}}\right)\right]\right] \\
& =e^{-\eta \Delta t} \cdot P \cdot \phi\left(-d_{1, T-\Delta t}\right) \cdot \frac{\partial d_{1, T-\Delta t}}{\partial X_{1, T-2 \Delta t}} \cdot \Phi\left(-d_{2, T-\Delta t}^{\mathrm{lag}}\right) \\
& +e^{-\eta \Delta t} \cdot P \cdot \Phi\left(-d_{1, T-\Delta t}\right) \cdot \phi\left(-d_{2, T-\Delta t}^{\mathrm{lag}}\right) \cdot \frac{\partial d_{2, T-\Delta t}^{\mathrm{lag}}}{\partial X_{1, T-2 \Delta t}} .
\end{aligned}
$$

Using Conditions (23), the following equations are obtained:

$$
\begin{aligned}
\frac{\partial d_{1, T-\Delta t}}{\partial X_{1, T-2 \Delta t}} & =\frac{1}{\sigma_{1} \sqrt{\Delta t}} \cdot \frac{-1}{\left(Q_{1, T-\Delta t} \cdot \Delta t\right) / a_{1}} \cdot\left(Q_{1, T-\Delta t} \cdot \Delta t\right) \cdot\left(a_{1}\right)^{-2} \cdot \frac{\partial a_{1}}{\partial X_{1, T-2 \Delta t}}=0, \\
\frac{\partial d_{2, T-\Delta t}^{\mathrm{lag}}}{\partial X_{1, T-2 \Delta t}} & =\frac{1}{\sigma_{2} \sqrt{2 \Delta t}} \cdot \frac{-1}{\left(Q_{2, T-2 \Delta t} \cdot 2 \Delta t\right) / b_{2}^{\mathrm{lag}}} \cdot\left(Q_{2, T-2 \Delta t} \cdot 2 \Delta t\right) \cdot\left(b_{2}^{\operatorname{lag}}\right)^{-2} \cdot \frac{\partial b_{2}^{\operatorname{lag}}}{\partial X_{1, T-2 \Delta t}}=0
\end{aligned}
$$

and hence $\left(\partial \bar{S}_{T-\Delta t}\right) /\left(\partial X_{1, T-2 \Delta t}\right)=0$. When the total emissions, $\int_{0}^{T-2 \Delta t} Q_{1, s} d s$, have already passed $\delta_{1, T-2 \Delta t}$, the spot price of the emission allowances at time $T-$ $2 \Delta t$ is simply equal to the discounted penalty, $e^{-\eta \Delta t} \cdot P$. Yet we have that $\left(\partial \bar{S}_{T-\Delta t}\right) /\left(\partial X_{1, T-2 \Delta t}\right)=0$. Thus, when total emissions do not exceed the net amount of permits, the spot price is 


$$
\begin{aligned}
\bar{S}_{T-2 \Delta t} & =e^{-\eta \Delta t} \cdot \mathbb{E}_{\mathbb{P}}\left[\bar{S}_{T-\Delta t} \mid \mathscr{F}_{T-2 \Delta t}^{1}\right] \\
& =e^{-\eta 2 \Delta t} \cdot P \cdot\left\{1-\mathbb{E}_{\mathbb{P}}\left[\mathcal{P}_{T-2 \Delta t}^{1} \mid \mathscr{F}_{T-2 \Delta t}^{1}\right]\right\} .
\end{aligned}
$$

Otherwise, the spot price is simply equal to $e^{-\eta 2 \Delta t} \cdot P$.

Similarly, solving the minimization problem corresponding to company $i=2$, when total emissions do not exceed the net amount of permits it follows:

$$
\begin{aligned}
\bar{S}_{T-2 \Delta t} & =e^{-\eta \Delta t} \cdot \mathbb{E}_{\mathbb{P}}\left[\bar{S}_{T-\Delta t} \mid \mathscr{F}_{T-2 \Delta t}^{2}\right] \\
& =e^{-\eta 2 \Delta t} \cdot P \cdot\left\{1-\mathbb{E}_{\mathbb{P}}\left[\mathcal{P}_{T-2 \Delta t}^{2} \mid \mathscr{F}_{T-2 \Delta t}^{2}\right]\right\} .
\end{aligned}
$$

Otherwise, the spot price is simply equal to $e^{-\eta 2 \Delta t} \cdot P$.

We generalize the proof for the time step $T-j \Delta t$ considering the following objective function that has to be minimized with respect to $X_{1, T-j \Delta t}$ :

$$
H \equiv\left\{S_{T-j \Delta t} \cdot X_{1, T-j \Delta t}+e^{-\eta \Delta t} \mathbb{E}_{\mathbb{P}}\left[\sum_{h=1}^{j} e^{-\eta(h-1) \Delta t} \bar{S}_{T-(j-h) \Delta t} \cdot \bar{X}_{1, T-(j-k) \Delta t} \mid \mathscr{F}_{T-j \Delta t}^{1}\right]\right\}
$$

Computing the FOC, it follows:

$$
\begin{gathered}
S_{T-j \Delta t} \cdot \frac{\partial \bar{X}_{1, T-j \Delta t}}{\partial X_{1, T-j \Delta t}}= \\
-e^{-\eta \Delta t} \mathbb{E}_{\mathbb{P}}\left[\sum_{h=1}^{j} e^{-\eta(h-1) \Delta t} \bar{S}_{T-(j-h) \Delta t} \cdot \frac{\partial \bar{X}_{1, T-(j-h) \Delta t}}{\partial X_{1, T-j \Delta t}}+\bar{X}_{1, T-(j-h) \Delta t} \cdot \frac{\partial \bar{S}_{T-(j-h) \Delta t}}{\partial X_{1, T-j \Delta t}} \mid \mathscr{F}_{T-j \Delta t}^{1}\right] .
\end{gathered}
$$

When the total emissions, $\int_{0}^{T-j \Delta t} Q_{1, s} d s$, have already passed the net amount of permits, $\delta_{1, T-j \Delta t}$, the spot price of the emission allowances at time $T-j \Delta t$ is simply equal to the discounted penalty, $e^{-\eta j \Delta t} \cdot P$. Otherwise, using Conditions (23) and Equation (24), the following equation is obtained:

$$
\bar{S}_{T-j \Delta t}=e^{-\eta \Delta t} \mathbb{E}_{\mathbb{P}}\left[\bar{S}_{T-(j-1) \Delta t} \mid \mathscr{F}_{T-j \Delta t}^{1}\right],
$$

hence

$$
\begin{aligned}
\bar{S}_{T-j \Delta t} & =e^{-\eta \Delta t} \mathbb{E}_{\mathbb{P}}\left[e^{-\eta(j-1) \Delta t} \cdot P \cdot\left\{1-\mathbb{E}_{\mathbb{P}}\left[\mathcal{P}_{T-j \Delta t}^{1} \mid \mathscr{F}_{T-(j-1) \Delta t}^{1}\right]\right\} \mid \mathscr{F}_{T-j \Delta t}^{1}\right] \\
& =e^{-\eta j \Delta t} \cdot P \cdot\left\{1-\mathbb{E}_{\mathbb{P}}\left[\mathcal{P}_{T-j \Delta t}^{1} \mid \mathscr{F}_{T-j \Delta t}^{1}\right]\right\} .
\end{aligned}
$$




\section{Appendix D}

Let us define $\mathscr{I}=\{1,2, \ldots, I\}$ the set of relevant companies. The existence of asymmetric information is modelled assuming that each company $i$ observes its accumulated pollution process and the accumulated (and aggregated) pollution process of the $\boldsymbol{I}^{-}$ companies with a lag, where $I^{-}:=\mathscr{I}-i$. Modelling the emission permit price in a multi-period and multi-firm framework requires solving $I$ minimization problems at each time step $k \in[1,2, \ldots, T / \Delta t]$. Along the line of Brigo et al. (2004), one can approximate the cumulative pollution process, $Q_{I^{-}, t}=\sum_{j=1, j \neq i}^{I} Q_{j, t}$, with a new geometric Brownian motion and obtain $I$ emission price equations as described in Section 4.2:

$$
\bar{S}_{T-k \Delta t}=e^{-\eta k \Delta t} \cdot P \cdot\left\{1-\mathbb{E}_{\mathbb{P}}\left[\mathcal{P}_{T-k \Delta t}^{i} \mid \mathscr{F}_{T-k \Delta t}^{i}\right]\right\},
$$

where

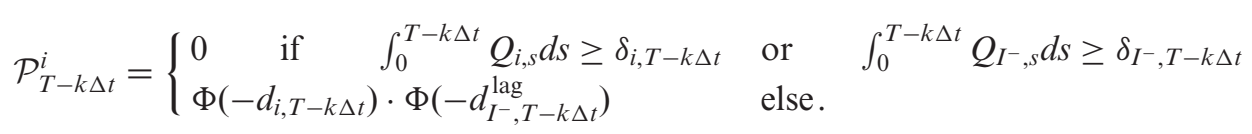

Using constant drift and volatility terms, $\left\{\mu \in \mathbb{R}^{I}\right.$ and $\left.\sigma \in \mathbb{R}^{+I}\right\}$, and relying on the standard technique of the methods of moments, we can determine the parameters of the new approximated geometric Brownian motion $Q_{I^{-}, t}$,

$$
\frac{d Q_{I^{-}, t}}{Q_{I^{-}, t}}=\mu_{I}-d t+\sigma_{I}-d W_{I^{-}, t}
$$

where $W_{I^{-}}$is a Brownian motion and

$\mu_{I^{-}}=\frac{1}{t} \ln \left(\frac{\sum_{j=1, j \neq i}^{I} Q_{j, 0} e^{\mu_{j} t}}{\sum_{j=1, j \neq i}^{I} Q_{j, 0}}\right), \quad \sigma_{I^{-}}^{2}=\frac{1}{t} \ln \left(\frac{\sum_{j, k=1, j, k \neq i}^{I} Q_{k, 0} Q_{j, 0} e^{\left(\mu_{k}+\mu_{j}+\rho_{k, j} \sigma_{k} \sigma_{j}\right) t}}{\left(\sum_{j=1}^{I} Q_{j, 0} e^{\mu_{j} t}\right)^{2}}\right)$.

Hence, when the total emissions have not passed the cap, we determine the equilibrium permit price solving a system of $I$ equations. More precisely, we numerically evaluate the quantity of permits that satisfies the following equalities at each time step $k \in[1,2, \ldots, T / \Delta t]:$

$$
\mathbb{E}_{\mathbb{P}}\left[\Phi\left(-d_{i, T-\Delta t}\right) \cdot \Phi\left(-d_{I^{-}, T-\Delta t}^{\mathrm{lag}}\right) \mid \mathscr{F}_{T-k \Delta t}^{i}\right]=\mathbb{E}_{\mathbb{P}}\left[\Phi\left(-d_{j, T-\Delta t}\right) \cdot \Phi\left(-d_{I^{-}, T-\Delta t}^{\mathrm{lag}}\right) \mid \mathscr{F}_{T-k \Delta t}^{j}\right],
$$

(for $\{i, j\} \in \mathscr{I}$ and $i \neq j$ ) and the market-clearing condition $\sum_{i=1}^{I} \bar{X}_{i, T-k \Delta t}=0$, for a given set of parameters $\left\{\mu \in \mathbb{R}^{I} \sigma\right.$ and $Q_{0} \in \mathbb{R}^{+I}$ and $\left.N_{0} \in N^{+I}\right\}$ that characterize the $I$ pollution processes. 